\title{
Reseña de Sentencias del Tribunal Constitucional sobre la Administración Local y Autonómica que aparecen publicadas en el BOE, durante el segundo semestre de 1995
}

\author{
Francisco Javier Fernández González \\ Profesor Titular de Derecho Administrativo \\ Universidad de Oviedo
}

Sumario: 1. CONFLICTOS DE COMPETENCIAS ENTRE COMUNIDADES AUTÓNOMAS. II. DERECHO PARLAMENTARIO. III. EMPLEO PÚBLICO. IV. RÉGIMEN ELECTORAL. V. JURISDICCIÓN CONTENCIOSO-ADMINISTRATIVA. VI. ACTIVIDAD SANCIONADORA. VII. EXPROPIACIÓN FORZOSA. VIII. URBANISMO. IX. DERECHO PÚBLICO DE LA ECONOMÍA: A) Telecomunicaciones. B) Agricultura: denominaciones de origen. X. ESPACIOS NATURALES Y MEDIO AMBIENTE.

\section{CONFLICTOS DE COMPETENCIAS ENTRE COMUNIDADES AUTÓNOMAS}

1. Conflicto positivo de competencia núm. 616/87, promovido por el Consejo de Gobierno de la Diputación Regional de Cantabria, frente al Gobierno del País Vasco, en relación con ciertos actos del Gobierno de la Gomunidad Autónoma del País Vasco realizados en el municipio de Villaverde de Trucios. El TC por un lado inadmite el conflicto respecto de algunos de los actos impugnados (los relativos a la realización de obras en el término municipal por personal funcionario y uniformado del Gobierno Vasco y también respecto a la extralimitación en materia de policía de carreteras e imposición de multas y sanciones dentro del territorio del municipio) por adolecer el requerimiento formulado por el Consejo de Gobierno de la Diputación Regional de Cantabria de una falta de concreción espacial y temporal en relación con dichos actos; por otro lado el TC declara que las medidas relativas a los análisis oficiales de las aguas en el municipio de Villaverde de Trucios si han invadido la competencia de la Comunidad Autónoma de Cantabria. 
«Ha de darse parcialmente la razón a la representación del Gobierno vasco en cuanto a que el requerimiento formulado por el Consejo de Gobierno de la Diputación Regional de Cantabria, al menos en lo que hace a una parte de su contenido, no cumple determinados requisitos formales y en consecuencia no sirve, en lo incumplido, a la finalidad primordial de generar las posibilidades de resolución convencional o negociada de las diferencias entre ambas Comunidades Autónomas, evitando el consiguiente enfrentamiento en un proceso constitucional.

Examinado desde esta perspectiva, de lo que básicamente adolece el mencionado presupuesto procesal es de una mínima concreción o determinación de algunos de los actos objeto del mismo, lo que conlleva, a su vez, una indeterminación del momento en que tuvieron lugar $\mathrm{y}$, consiguientemente, una imposibilidad de control del plazo preceptivo de dos meses para su formulación establecido en el artículo 63.2 LOTC.

En efecto, el requerimiento del Consejo de Gobierno de la Diputación Regional de Cantabria, acordado en la reunión celebrada el día 19 de febrero de 1987, con fecha de salida del Registro General de la Diputación Regional de Cantabria, de 10 de marzo de 1987, se refiere a «la realización de análisis oficiales de las aguas de la red de Villaverde de Trucíos», a «la realización de obras en el término municipal de Villaverde de Trucíos por personal funcionario y uniformado del Gobierno vasco» y a «la extralimitación en materia de Policía de carreteras e imposición de multas y sanciones dentro del territorio del municipio de Villaverde de Trucíos", actos todos ellos imputados al Gobierno vasco. No se recurre, pues, contra un acto, que por su forma y naturaleza facilitara su identificación en cuanto al objeto y en cuanto al plazo de requerimiento, sino contra una actuación de hecho, lo que exigía de la parte requirente una mayor concreción espacial y temporal de los actos imputados a la contraparte que la que resulta de la parquedad del requerimiento así formulado.

Así las cosas, lo cierto es que, sólo el primero de los actos imputados al Gobierno vasco, esto es, la realización de análisis oficiales de las aguas de la red del municipio de Villaverde de Trucíos, ofrece la suficiente concreción - y así parece aceptarlo también el Letrado de la Comunidad Autónoma de Cantabria en su escrito de demanda- como para constituir, en este caso, el objeto de un conflicto competencial. No cabe alegar inconcreción o indeterminación de este acto, como hace la representación del Gobierno vasco, cuando el mismo le sirvió para elaborar un informe sobre la potabilidad de las aguas del municipio de Villaverde de Trucíos que luego remitió al Jefe de Sanidad Local de dicho municipio, como así queda documentado en autos. 
RESEÑA DE SENTENCIAS DEL TRIBUNAL CONSTTTUCIONAL SOBRE LA ADMINISTRACIÓN LOCAL...

De las otras actuaciones que la representación de Cantabria imputa al Gobierno vasco, esto es, «la realización de obras en el término municipal de Villaverde de Trucíos por personal funcionario y uniformado del Gobierno vasco" y "la extralimitación en materia de Policía de carreteras e imposición de multas y sanciones dentro del territorio del municipio de Villaverde de Trucíos", resulta imposible su concreción fáctica y temporal y, en consecuencia, también computar el preceptivo plazo de dos meses a contar desde el día siguiente al momento en que estos actos se llevaron a cabo hasta la formulación del requerimiento. Por ello, dichos actos no pueden constituir objeto del presente conflicto de competencias, siendo innecesario un pronunciamiento sobre el recibimiento a prueba solicitado en el primer otrosí de la demanda.

En suma, únicamente el acto relativo a la realización de análisis oficiales de las aguas de la red del municipio de Villaverde de Trucíos puede ser objeto del presente conflicto competencial, porque con la aportación del documento referido junto a la demanda se ha concretado el acto, el sujeto, el lugar y el plazo, y, por tanto, ha permitido a este Tribunal advertir, el conocimiento cierto que tenía el Gobierno vasco del acto cuando fue requerido de incompetencia» (vid. f.j. 3).

«La realización por parte del Servicio Vasco de Salud de análisis oficiales de las aguas del municipio de Villaverde de Trucíos y la comunicación del resultado de los mismos al Jefe Local de Sanidad de dicho municipio, en el que se añadía el deber de adoptar a la mayor brevedad posible las medidas oportunas para la corrección de la no potabilidad del agua, supone, entendido el acto como un todo, un acto formal de una autoridad propia que, por medio de hechos concretos dentro de una actuación material de sus potestades, expresa una afirmación de competencia que invade el ejercicio de competencias que corresponden a la Comunidad Autónoma de Cantabria.

En efecto, no se trata aquí de un conflicto potencial o cautelar, virtual o hipotético por el que se pretenda que juzguemos la sospecha de que una determinada actuación tiene como finalidad última la vulneración del orden competencial. Se trata, por el contrario, de un conflicto real en el que se juzga, como ya aconteciera en la STC 33/1982 un acto conminatorio del Gobierno vasco, cual es la comunicación ahora enjuiciada a un funcionario de un Ayuntamiento que no pertenece a su territorio, y sobre el cual carece de toda competencia. El tenor literal de la comunicación del Gobierno vasco al Jefe de Sanidad Local de Villaverde de Trucíos (adjunto le remito resultados analíticos obtenidos en aguas de su municipio. Por ser, en las muestras que se indican, su cali- 
ficación «no potable» deberá adoptarse a la mayor brevedad posible las medidas oportunas para su corrección") pone de manifiesto que no estamos ante un acto meramente informativo o una simple actuación de hecho, como pretende la representación del Gobierno vasco, sino ante un acto de afirmación de poseer una competencia que, en este caso, correspondía a la Comunidad Autónoma de Cantabria, única autoridad, por lo dicho, que podía conminar al citado Ayuntamiento a tomar las medidas pertinentes» (vid. f.j. 7).

Fallo: $10^{\circ}$ Inadmitir el conflicto respecto de los actos relativos a «la realizacion de obras en el término municipal de Villaverde de Trucíos por personal funcionario y uniformado del Gobierno vasco" y a «la extralimitación en materia de policía de carreteras e imposición de multas y sanciones dentro del territorio del municipio, de Villaverde de Trucíos».

2. ${ }^{\circ}$ Respecto de las medidas relativas a los análisis oficiales de las aguas en el municipio de Villaverde de Trucios, declarar que han invadido la competencia de la Comunidad Autónoma de Cantabria.

3. Desestimar el conflicto en todo lo demás.

(Sentencia n. ${ }^{\circ}$ 101/1995, de 22 de junio. Pleno. BOE 24-7-1995. A. Rodríguez Bereijo. Voto particular formulado por M. Jiménez de Parga y Cabrera).

\section{DERECHO PARLAMENTARIO}

1. Recurso de amparo núm. 739/93, promovido por el Grupo Parlamentario Popular de las Cortes Valencianas contra Resolución de la Mesa de las Cortes Valencianas de 15 de diciembre de 1992 por la que se inadmiten a trámite determinadas enmiendas presentadas por el Grupo Parlamentario Popular al Proyecto de Ley de Presupuestos de la Generalidad Valenciana para 1993. Los demandantes de amparo entienden vulnerado el derecho fundamental establecido en el artículo 23.2 CE. El TC otorga el amparo.

«La tercera de las cuestiones sometidas a la consideración de este Tribunal se refiere a la viabilidad jurídica de enmiendas de proyección de gasto futuro que no incidan sobre el Presupuesto objeto de debate. Pretende el Grupo Parlamentario Popular que este Tribunal se pronuncie sobre la constitucionalidad de ese tipo de enmiendas de gasto cero. 
RESEÑA DE SENTENCIAS DEL TRIBUNAL CONSTTTUCIONAL SOBRE LA ADMINISTRACIÓN LOCAL...

Pero resolver esa cuestión en los terminos planteados en la demanda resulta del todo innecesario en la medida en que, por sí mismas, la viabilidad o inviabilidad de este tipo de enmiendas no puede reputarse lesiva de ningún derecho fundamental.

Cuestión distinta es el criterio al que la Mesa de la Cámara, en tanto que órgano de organización y gobierno interior de la Asamblea, decida acogerse en la tramitación y sustanciación del procedimiento presupuestario. A ella, y no a este Tribunal, incumbe decidir sobre la viabilidad, o inviabilidad, de este tipo de enmiendas; decisión de carácter puramente parlamentario que no constituye, en sí misma, lesión alguna de derechos fundamentales y que se integra, esta vez sí, en el ámbito de los interna corporis acta, formando parte, en consecuencia, de la libertad de decisión que le garantiza su propia autonomía institucional.

Ahora bien, adoptado un criterio, en uno u otro sentido, es exigencia del artículo 23.2 C.E. que el mismo se aplique por igual a todas las enmiendas de esa naturaleza presentadas por los distintos Grupos Parlamentarios, sin establecerse un criterio selectivo de admisión que resulte arbitrario, desigual y, por tanto, lesivo del derecho que la Constitución garantiza a los cargos públicos para un ejercicio de sus funciones en condiciones de igualdad.

Se sostiene en la demanda de amparo que las enmiendas de gasto cero rechazadas al Grupo recurrente son idénticas en su estructura y redacción a algunos de los apartados contenidos en el Proyecto de Ley de Presupuestos y a otras enmiendas que, sin embargo, sí fueron admitidas. Y, en efecto, examinadas las actuaciones parlamentarias, es de apreciar que las enmiendas de gasto cero no vienen siendo excluidas de raíz por las Cortes Valencianas, no siendo infrecuente que el propio Consejo estructure su Proyecto presupuestario en la utilización de ese tipo de programaciones diferidas del gasto público. En consecuencia, y en la medida en que lo anterior evidencia que la inadmisión de varias de las enmiendas de este tipo presentadas por el Grupo recurrente ha supuesto un trato discriminatorio, por desigual y por no poner de manifiesto los motivos de ese trato respecto del caso concreto o del cambio del criterio general, procede estimar, en este concreto punto, la demanda de amparo.

Fallo: Estimar parcialmente el presente recurso de amparo y, en consecuencia:

1. Reconocer el derecho del Grupo Parlamentario Popular de las Cortes Valencianas a ser tratado en condiciones de igualdad en el trá- 
mite de admisión de enmiendas de gasto cero al Proyecto de Ley de Presupuestos de la Generalidad Valenciana.

2. Desestimar el recurso en todo lo demás.

(Sentencia n. ${ }^{\circ} 118 / 1995$, de 17 de julio. Sala Segunda. BOE 22-81995. C. Viver Pi-Sunyer).

2. Recurso de amparo núm. 2.208/94, promovido por el Portavoz del Grupo Parlamentario de Izquierda Unida en la Asamblea Regional de Murcia, contra las Resoluciones de la Mesa del citado Parlamento autonómico, de 22 de febrero y 15 de marzo de 1994, por los que se declaraba la inadmisión a trámite de la proposición de Ley núm. 21 de Reforma de la Ley 6/1988, de 25 de agosto, de Régimen Local de la Región de Murcia, en base a un juicio material acerca de la eventual inconstitucionalidad de parte de sus contenidos. A juicio del demandante de amparo se ha vulnerado su derecho a ejercer su función parlamentaria en condiciones de igualdad, con arreglo a lo dispuesto en el Reglamento de la Cámara, ex artículo 23.2 CE. El TC otorga el amparo.

"Habiéndose constatado que la Mesa de la Cámara inadmitió la referida proposición de Ley, mediante un pretendido juicio de constitucionalidad acerca de sus contenidos, cuando la misma cumplía con todas las formalidades reglamentariamente establecidas, la presente demanda de amparo debe ser estimada. Con tal proceder, la Mesa extralimitó sus funciones reglamentarias de calificación y admisión a trámite de documentos parlamentarios que, cuando de proposiciones de Ley de origen parlamentario se trata, se circunscriben exclusivamente, y por la naturaleza de éstas, a la mera comprobación del cumplimiento de aquellas exigencias formales. Los acuerdos impugnados exceden lo que es propio de un control de constatación formal para justificar la inadmisión de la proposición de Ley en razones de contenido, impidiendo así, al parlamentario recurrente, y a los demás miembros del Grupo Parlamentario proponente de la iniciativa, el ejercicio de sus derechos parlamentarios con arreglo a lo dispuesto en el Reglamento de la Cámara, por lo que debemos declarar que se ha vulnerado el derecho fundamental que les reconoce el artículo 23.2 de la Constitución, en relación con el apartado primero de ese mismo artículo» (vid. f.j. 4).

Fallo: Estimar el recurso de amparo y, en consecuencia, declarar la nulidad de los Acuerdos de la Mesa de la Asamblea Regional de Murcia, 
RESEÑA DE SENTTENCIAS DEL TRIBUNAL CONSTITUCIONAL SOBRE LA ADMINISTRACIÓN LOCAL...

de 22 de febrero y 15 de marzo de 1994, por los que se declara la inadmisión a trámite de la proposición de Ley núm. 21 de Reforma de Ia Ley 6/1988, de 25 de agosto, de Régimen Local de la Región de Murcia.

(Sentencia n. ${ }^{\circ}$ 124/1995, de 18 de julio. Sala Primera. BOE 22-81995. V. Gimeno Sendra).

\section{EMPLEO PÚBLICO}

1. Recurso de amparo núm. 2.584/92, promovido contra la Resolución de la Alcaldía de Valencia, de 2 de noviembre de 1988, confirmada en reposición por la de 6 de febrero de 1989, por las que se realizan los nombramientos en propiedad de auxiliares administrativos, derivados de la convocatoria efectuada por Acuerdo Plenario de 10 de julio de 1986, asi como contra la Sentencia de la Sala de lo Contencioso-Administrativo del Tribunal Superior de Justicia de Valencia, de 29 de septiembre de 1992, que confirma dichas Resoluciones del Ayuntamiento. Los recurrentes entienden que las Resoluciones de la Alcaldía de Valencia impugnadas atentan contra sus derechos fundamentales, reconocidos en los artículos 14 y 23.2 C.E., por cuanto nombran funcionarios en propiedad a quienes han utilizado los puntos obtenidos al valorar la antigüedad como mérito para superar los tres ejercicios de que constaba la oposición; si bien reconocen que los méritos están admitidos como aplicables en nuestro ordenamiento, los consistentes en haber prestado servicios, como contratados e interinos, que deben computarse y valorarse, no pueden suplir la falta de capacidad, puesto que el artículo 23.2, en relación con el 103.3 C.E., obliga a respetar en todo caso la capacidad; en relacion con los aspectos formales de su demanda, consideran que la circunstancia de no haber impugnado las bases que han dado lugar a las Resoluciones recurridas, no es obstáculo para la viabilidad de la pretensión que se formula, porque la lesión no la producen las bases sino los actos administrativos recurridos. El TC otorga el amparo. núm. 1.623/94.

"La cuestión de fondo planteada suscita de nuevo el tema de si es contrario a los artículos 14 y 23.2 C.E. el que los puntos obtenidos en la fase de concurso (incluyendo los que se conceden por el tiempo de servicios prestados en régimen de interinidad en la Administración) puedan computarse también en la fase de oposición. En concreto, las bases que ahora se enjuician convocan el acceso a las plazas - como se recoge en los antecedentes- mediante el sistema de oposición libre, a tra- 
vés de tres ejercicios cuya puntuación mínima de aprobado es la de cinco puntos en cada uno de ellos. La base tercera de dicha convocatoria regula la valoración, con carácter previo a la oposición libre, de los servicios prestados por el personal contratado administrativo y funcionarios interinos conforme con los siguientes criterios: Los servicios prestados hasta la fecha de presentación de instancias, como interino o contratado administrativo, se valorarán a razón de 0,20 puntos por mes, sin que su total pueda superar el 45 por 100 del máximo total de puntos que puedan obtenerse con las pruebas selectivas. Los puntos así obtenidos se aplicarán consuntivamente a cada uno de los ejercicios de la oposición, de manera que puedan sumarse a los obtenidos en la calificación de éstos, hasta alcanzar así la puntuación mínima establecida en la convocatoria para superar cada uno de los ejercicios. Los restantes puntos se sumarán a la puntuación final a efectos de establecer el orden definitivo de aprobados.

Los solicitantes de amparo entienden que esta valoracion favorece, de una forma arbitraria y desproporcionada, conculcando los artículos 14 y 23.2 C.E., a quienes han tenido ocasión de prestar previamente servicios en la Administración convocante puesto que dichos servicios, como contratados o interinos, suplen la falta de capacidad al ser aplicados a aquellos que no alcanzan el nivel de conocimientos genéricos o específicos en los ejercicios correspondientes. La lesión, por lo tanto, no se imputa al sistema en su conjunto, pues como los propios recurrentes admiten, la consideración de los servicios prestados no es ajena al concepto de mérito y capacidad, sino sólo al apartado $3 .^{\circ}$ de la base tercera de la convocatoria según el cual los puntos obtenidos en la fase de concurso pueden también computarse en la fase de oposición" (f.j. 6).

«Precisada así la causa petendi de los recurrentes, el supuesto que plantean guarda estrecha relación con el resuelto en la STC 67/1989 en la que los allí demandantes solicitaron amparo ante este Tribunal, entre otras causas, porque en las bases de la convocatoria cuestionada se preveía que los puntos obtenidos en la fase de concurso podían computarse también en la fase de oposición. Rechazadas las otras cuestiones que suscitaban los recurrentes, este Tribunal otorgó el amparo solicitado al considerar contrario al art. 23.2 C.E. el sistema de valoración descrito pues, como se indica en el fundamento jurídico $5 .^{\circ}$ de la referida Sentencia, «la aplicación de los puntos obtenidos en la fase de concurso a cada uno de los ejercicios obligatorios de la fase de oposici6n, para permitir alcanzar, en su caso, la puntuación mínima establecida para aquéllos en la convocatoria, supone una diferencia no razonable y arbitraria de trato entre 
RESEÑA DE SENTENCLAS DEL TRIBUNAL CONSTITUCIONAL SOBRE LA ADMLNISTRACIÓN LOCAL...

quienes concurren a la oposición, habiendo prestado un breve tiempo de servicios como contratados e interinos y los demás opositores a quienes en la fase de concurso no se les valoraron otros méritos".

El mismo criterio, en consecuencia, debe seguirse aquí. Porque esta desigualdad de trato que se prevé en el apartado $3 .^{\circ}$ de la base tercera de la convocatoria, en cuanto al nivel de exigencia entre unos y otros opositores, por la sola razón de la existencia o no de un período previo de servicios administrativos, ha de ser estimada como incompatible con los principios de mérito y capacidad. Por ello, ha de declararse que son contrarias al art. 23.2 C.E. y que lesionan el derecho a la igualdad en el acceso a las funciones públicas de los solicitantes de amparo las Resoluciones de nombramiento impugnadas en tanto y en cuanto dichos nombramientos hayan sido posibles en aplicación del apartado $3 .^{\circ}$ de la base tercera de la convocatoria, según el cual «Los puntos así obtenidos se aplicarán consuntivamente por la Comisión Permanente de Selección a cada uno de los ejercicios de la fase de oposición, de forma tal que se sumen a los obtenidos en la calificación de éstos los necesarios para alcanzar, en su caso, la puntuación mínima establecida en la convocatoria para poder superar cada uno de los mismos"» (vid. f.j. 7).

«Por lo que respecta al alcance del fallo, la declaración de este Tribunal ha de concretarse al reconocimiento y restablecimiento del derecho de los recurrentes. Por lo tanto debe contener una declaración de nulidad de las Resoluciones de la Alcaldía de Valencia de 2 de noviembre de 1988 y 6 de febrero de 1989, en tanto que estas últimas, adoptadas conforme a los dispuesto en el apartado $3 .^{\circ}$ de la base tercera de la convocatoria, atentan contra el art. 23.2 C.E. Asimismo, y en cuanto que confirma la validez de dichas resoluciones, ha de anularse la Sentencia de 29 de septiembre de 1992, dictada por la Sala de lo Contencioso-Administrativo del Tribunal Superior de Justicia de Valencia. De acuerdo con el artículo 55.1 a) de la LOTC, corresponde declarar a este Tribunal la extensión de los efectos de esta declaración de nulidad, lo que permite disponer la conservación de aquellos actos cuyo contenido hubiera permanecido el mismo de no haberse cometido la infracción de aquel derecho en la valoración establecida en el apartado $3 .^{\circ}$ de la base tercera de la convocatoria, preservándose así el nombramiento de quienes aprobaron los ejercicios de la fase de oposición sin necesidad de que se le aplicasen puntos obtenidos en la fase de concurso y anulando el de aquellos que ocuparon la plaza mediante este procedimiento» (f.j. 8).

Fallo: Estimar la demanda de amparo y, en su virtud: 
1. Reconocer el derecho de los solicitantes de amparo a la igualdad en el acceso a las funciones y cargos públicos establecido en el artículo 23.2 de la Constitución.

2. ${ }^{\circ}$ Declarar la nulidad de las Resoluciones de la Alcaldía de Valencia de 2 de noviembre de 1988 y 6 de febrero de 1989 preservando el nombramiento de quienes aprobaron los ejercicios de la fase de oposición sin necesidad de que se le aplicasen puntos obtenidos en la fase de concurso.

3. Declarar la nulidad de la Sentencia de 29 de septiembre de 1992, dictada por la Sala de lo Contencioso-Administrativo del Tribunal Superior de Justicia de Valencia.

(Sentencia n. ${ }^{\circ}$ 93/1995, de 19 de junio. Sala Segunda. BOE 24-71995. F. García-Mon y González-Regueral).

2. Recurso de amparo núm. 71/92, interpuesto contra la desestimación presunta, por silencio administrativo, de la petición formulada al Ayuntamiento de Gijón el 10 de junio de 1991 sobre levantamiento de la suspensión preventiva de funciones, impuesta cautelar y accesoriamente respecto del procedimiento penal que se le seguía por un delito. de prostitución, y contra la Sentencia de 17 de diciembre de 1991 de la Sala de lo Contencioso-Administrativo del Tribunal Superior de Justicia del Principado de Asturias, que desestimó el recurso interpuesto contra la desestimación presunta municipal. El recurrente entiende que tanto el acto presunto como la sentencia que impugna vulneran el derecho del artículo $23.2 \mathrm{CE}$, de permanencia en su puesto de funcionario, al no levantar la suspensión cautelar a pesar de conocer que en la causa penal fue condenado por tiempo inferior al que ya llevaba suspenso en sus funciones. El TC otorga el amparo.

«Haber mantenido la medida cautelar más allá de la desaparición del procesamiento por su metamorfosis en condena, límite legal infranqueable, y aun más allá de la duración de la pena accesoria materialmente idéntica, impuesta en la Sentencia, transgrede el perímetro legítimo de la suspensión y la proporcionalidad exigible respecto de la finalidad que persigue o la función objetiva que cumple (SSTC 108/1984 y 66/1989). En efecto, cuando la medida pierde su naturaleza cautelar, se convierte en una pena o sanción autónoma y atípica impuesta de plano, sine strepitu et uiditio, con infracción notoria del principio de le- 
galidad que rige el ius puniendi en sus manifestaciones penal o administrativa y se proclama en el artículo 25 de nuestra Constitución. Por otra parte, cuando la suspensión se prolonga de hecho indefinidamente, equivale a la separación del servicio, sanción maxima en su especie. No se olvide, desde otra perspectiva, que el mantenimiento de esta situación se ha hecho intuitu personae, por ser quien es y lo que es el funcionario suspenso, no en virtud del hecho incriminado sino de la personalidad de su autor, con un patente talante discriminatorio que rompe arbitrariamente la igualdad de condiciones en el ejercicio del cargo público desempeñado. En definitiva, tal desposesión del puesto de trabajo, temporal en principio pero en la realidad sine die, perpetra una clara agresión al derecho del servidor de la función pública a ejercerla sin ser discriminado y, por tanto, en condiciones de igualdad (artículo 23.2 $\mathrm{CE}$ ). En conclusión, merece el amparo quien lo pide ahora y en la misma medida que lo pide» (vid. f.j. 2).

Fallo: Estimar el recurso de amparo y, en su virtud:

1. Reconocer el derecho del recurrente a ser mantenido sin discriminación alguna en su condición de funcionario del Ayuntamiento de Gijón y, en consecuencia, a ser repuesto en el desempeño de la plaza de funcionario que venía detentando en la Corporación.

2. Declarar la nulidad de la resolución presunta de la mencionada Corporación municipal, por la que se denegó la petición formulada por el recurrente el día 10 de junio de 1991 sobre levantamiento de la medida cautelar de suspensión provisional de funciones, acordada con ocasión de su procesamiento, y de la Sentencia de la Sala de lo Contencioso-Administrativo del Tribunal Superior de Justicia del Principado de Asturias, de 17 de diciembre de 1991, que declaró conforme a la Constitución aquella decisión municipal.

(Sentencia n. ${ }^{\circ}$ 104/1995, de 3 de julio. Sala Segunda. BOE 31-7-1995. R. de Mendizábal Allende).

\section{RÉGIMEN ELECTORAL}

1. Recurso de amparo electoral núm. 2495/95, promovido por el Partido Popular contra la Sentencia del Tribunal Superior de Justicia de Castilla-La Mancha, de 30 de junio de 1995, recaida en recurso contencioso-administrativo electoral contra los Acuerdos de 7 de junio de 1995, de la Junta Electoral Central y, de 9 de junio de 1995, de la Junta 
Electoral de Zona, sobre proclamación de electos del municipio de El Casar (Guadalajara). El partido político solicitante de amparo entiende que se ha vulnerado el art. 23.2 CE, al declarar la validez de la elección y proclamación de electos del Municipio de El Casar no aceptando como válida la papeleta anulada y computando los decimales en los cocientes para el cálculo de escaños. El TC deniega el amparo.

«En cuanto al fondo del asunto, plantean los recurrentes una posible infracción del artículo 23.2 CE con base a dos motivos distintos. Por una parte, porque la resolución impugnada no reconoce la validez de un voto emitido en la Mesa 1-1-B que fue anulado por encontrarse la papeleta con un "garabato", sin que se tachase, no obstante, a ninguno de los candidatos propuestos por el partido. Por otra parte, porque en la adjudicación del escaño en litigio en los cocientes se ha computado el cálculo de decimales.

Comenzando por la primera línea de razonamiento de la demanda, debe traerse a colación nuestra doctrina sobre la interpretación de los requisitos establecidos en el art. 96.2 de la L.O.R.E.G. en el que se dispone que «en el caso de elecciones al Congreso de los Diputados, al Parlamento Europeo, a los Ayuntamientos y a los Cabildos Insulares serán también nulos los votos emitidos en papeletas en las que se hubiera modificado, añadido, señalado o tachado nombres de los candidatos comprendidos en ella o alterado su orden de colocación, así como aquellas en las que se hubiera producido cualquier otro tipo de alteración", sea ésta de las papeletas (artículo 96.2 C.E.) o de los sobres que las contienen (artículo 96.4 C.E.). En este sentido, en la STC 165/1991 tuvo ocasión' de precisarse que en este precepto se recoge «el llamado principio de inalterabilidad de la lista electoral». Es patente -continúa diciéndose en el Fundamento Jurídico $3^{\circ}$ - que la nueva regulación ha introducido una cláusula general de cierre - «cualquier otro tipo de alteración»- y ha sumado otros participios - «añadido», «señalado»- a los ya presentes, con la finalidad de enfatizar la prohibición de señales o manipulaciones de cualquier tipo en las papeletas de voto, precisamente por su carácter de papeletas que incorporan listas bloqueadas y cerradas en las que no es menester indicación alguna del elector al emitir el sufragio. Por lo tanto, «el entendimiento de cuándo procede y cuándo no la aplicación de lo dispuesto en el artículo 96.2 de la L.O.R.E.G. configura normalmente un juicio de estricta legalidad electoral que no puede ser revisado por este Tribunal, una vez comprobado que la interpretación seguida por el órgano judicial ordinario no es arbitraria, irrazonada o irrazonable» (STC 165/1991). 
RESEÑA DE SENTENCIAS DEL TRIBUNAL CONSTITUCIONAL SOBRE LA ADMINISTRACION LOCAL...

En el presente caso, y en este punto, no cabe tachar de arbitraria, irrazonada o irrazonable la sentencia impugnada cuando confirma la invalidez del voto emitido en la Mesa 1-1-B del municipio de El Casar, por aparecer el mismo en una papeleta garabateada, tanto más cuanto esta resolución fundamenta su decisión en la jurisprudencia constitucional mencionada. En consecuencia, no puede apreciarse lesión del derecho fundamental proclamado en el artículo $23.2 \mathrm{CE}$ por este primer motivo» (f.j. 5).

«En una segunda línea argumental, los actores entienden violado el derecho de acceso en condiciones de igualdad a los cargos públicos porque en la adjudicación del escaño en litigio los cocientes, resultado de las operaciones aritméticas que prescribe el artículo 163 de la L.O.R.E.G. que sirven para la atribución de los distintos escaños, han sido computados incluyendo en ellos el cálculo de decimales. Con esta alegación, los recurrentes introducen un problema de interpretación del artículo 163 de la L.O.R.E.G sobre el que, ante el silencio aparente de la norma, debe ahora pronunciarse este Tribunal» (vid. f.j. 6).

«Así las cosas, por las razones anteriormente expuestas y por las que se acaban de manifestar, es necesario dilucidar la cuestión de si constituye una interpretación razonable que en el cómputo de cocientes establecido en el artículo 163 de la L.O.R.E.G. debe entenderse incluido el de las fracciones decimales resultantes de aquellas operaciones, o por el contrario, éstas deben ser despreciadas en el mismo. De hecho, pues, en el fondo lo que se plantea es una concreción del término de "empate» entre dos candidaturas a los efectos de aplicación del artículo $163.11 \mathrm{~d}$ ) L.O.R.E.G.

La fórmula electoral de la llamada Regla d'Hondt, contenida en el artículo 163 de la L.O.R.E.G, consiste en un mecanismo matemático en virtud del cual se procede a la atribución de escaños o, como en el presente caso, los puestos de Concejales en cada Ayuntamiento con base a una serie de reglas. Entre ellas, el apartado 1.c) del mencionado precepto indica que "Los escaños se atribuyen a las candidaturas que obtengan los cocientes mayores en el cuadro, atendiendo a un orden decreciente». "Cuando en la relación de cocientes - continúa el apartado 1.d ) - coincidan dos correspondientes a distintas candidaturas, el escaño se atribuirá a la que mayor número total de votos hubiese obtenido".

La Ley prevé, pues, una norma general para la atribución de escaños en función del resultado de los cocientes, obtenidos a través de sucesivas divisiones de los votos obtenidos por cada candidatura, de mayor a 
menor. Y prevé, a su vez, una regla subsidiaria - subsidiaria en el sentido de que de la anterior no pueda obtenerse otro resultado- para atribuir, en caso de coincidencia absoluta de cocientes, un escaño. Siendo ésta la estructura del precepto, cabe entender que la operación matemática en que consiste la regla general, se agota si la misma se lleva hasta el final, esto es, si el cociente resultante incluye su parte entera y decimal.

Así, de las dos interpretaciones que se aportan en el presente caso de la regla establecida en el artículo 163.1.c) de la L.O.R.E.G. ningún reproche constitucional merece la que entiende que los escaños (o los puestos de Concejales en cada Ayuntamiento) se atribuyen a las candidaturas que obtengan los cocientes mayores en el cuadro, en su parte entera y decimal, atendiendo a un orden decreciente.

En consecuencia, la Sentencia impugnada no ha vulnerado el artículo 23.2 CE al computar los números enteros y sus decimales en el cálculo de los cocientes, puesto que ésta es una interpretación razonable de la regla establecida en el artículo 163 de la L.O.R.E.G.» (f.j. 7).

Fallo: Denegar el amparo solicitado.

(Sentencia n. ${ }^{\circ} 115 / 1995$, de 10 de julio. Sala Primera. BOE 3-8-1995. E. Ruiz Vadillo).

2. Recurso de amparo núm. $2.745 / 95$ interpuesto contra la Sentencia de la Sala de lo Contencioso-Administrativo del Tribunal Superior de Justicia de la Comunidad Valenciana, de fecha 12 de julio de 1995, dictada en recurso contencioso-electoral contra los actos de constitución de la Corporación local de Almenara (Castellón) y de elección y proclamación de Alcalde del citado municipio. Los demandantes denuncian una doble violación de derechos constitucionales: el derecho de acceso a cargo público del artículo 23.2 de la C.E. y el derecho a la tutela judicial efectiva con interdicción de la indefensión, en un proceso con todas las garantías donde se respeten la contradicción e igualdad de las partes, a tenor de lo dispuesto en el artículo 24.1 y 2 de la C.E. Apoyan su alegato, en primer lugar, en no haber sido emplazados directa y personalmente en el recurso contencioso-electoral y, en segundo lugar, en que, una vez conocida la existencia del procedimiento y personados en el mismo, la Sala de lo Contencioso-Administrativo acordó la no retroacción del procedimiento, impidiéndoles formular alegaciones. El TC deniega el amparo. 
RESEÑA DE SENTENCIAS DEL TRIBUNAL CONSTTTUCIONAL SOBRE LA ADMINISTRACIÓN LOCAL..

«Procede, ante todo, desestimar, por carecer manifiestamente de contenido constitucional, la queja de habérseles impedido el derecho de acceso a cargo público, reconocido en el artículo 23.2 de la C.E., toda vez que la Sentencia del Tribunal de Justicia, objeto hoy de impugnación, no cuestionó en ningún momento la condición de los recurrentes de concejales electos para el Ayuntamiento de Almenara. Esto es, emplazados o no regularmente en el proceso contencioso electoral, la eventual indefensión no tuvo efecto sobre su derecho fundamental de sufragio pasivo" (f.j. 2).

«En el supuesto presente, se trata de una elección de Alcalde y conforme a lo dispuesto en el artículo 196 de la L.O.R.E.G. son candidatos los concejales que encabecen una lista, condición que no reúnen los quejosos. La legitimación para interponer el recurso contencioso-electoral, o para oponerse a los que se interpongan, está reservada a los candidatos, proclamados o no proclamados, junto a los representantes de las candidaturas y a los partidos, asociaciones, federaciones y coaliciones (artículo 110 L.O.R.E.G.).

Los recurrentes, en suma, no tenían que ser personalmente emplazados, ya que el representante de su candidatura lo fue en debida forma, correspondiéndole a éste comunicar a los concejales electos la existencia del proceso ante el Tribunal Superior de Justicia de la Comunidad Valenciana. La falta de diligencia de los recurrentes en amparo, el personarse tardíamente, les privó del trámite de alegaciones.

No cabe apreciar, por tanto, indefensión de clase alguna, así como tampoco falta de garantías procesales» (f.j. 4).

Fallo: Desestimar el recurso de amparo.

(Sentencia n. ${ }^{\circ} 155 / 1995$, de 24 de octubre. Sala Primera. BOE 28-111995. M. Jiménez de Parga y Cabrera).

\section{JURISDICCIÓN CONTENCIOSO-ADMINISTRATIVA}

1. Recurso de amparo núm. 2.072/92, promovido por el Ayuntamiento de Domeño (Valencia), contra la Sentencia de la Sección Sexta de la Sala Tercera del Tribunal Supremo, de 22 de junio de 1992, que estimó el recurso de apelación interpuesto contra la dictada por la Sección Segunda de la Sala de lo Contencioso-Administrativo del Tribunal Superior de Justicia de Valencia el 2 de abril de 1990, que habia inadmitido 
el recurso interpuesto por la Sociedad de Cazadores de Domeño contra las Resoluciones del mencionado Ayuntamiento y de la Consejería de Agricultura de la Generalidad Valenciana. Considera el Ayuntamiento recurrente que dicha resolución es contraria a su derecho a la tutela judicial efectiva (artículo 24.1 C.E.) al no contener pronunciamiento alguno sobre las objeciones de carácter formal frente a la admisión del recurso que se habian formulado tanto en la instancia como en la posterior apelación y que eran, básicamente, la falta de legitimación de los recurrentes, la existencia de litispendencia penal y una tercera alegación, de contornos menos precisos, consistente en la falta de respeto por parte de los recurrentes de un acto administrativo no declarado nulo, en clara contradicción con el principio de ejecutividad de tales actos; se reprocha, en definitiva, a la referida resolución un vicio de incongruencia omisiva lesivo del derecho a la tutela judicial efectiva. El TC otorga el amparo.

«De la documentación obrante en autos se desprende con toda claridad que las causas de inadmisión que se entienden no contestadas por la Sentencia recurrida fueron efectivamente planteadas - al menos las que resultan especialmente relevantes: la falta de legitimación de la Sociedad recurrente y la existencia de una litispendencia penal - en la contestación inicial al recurso contencioso-administrativo y en la posterior oposición a la apelación. Por otra parte, se trata de causas de inadmisibilidad del recurso que, evidentemente, tienen relevancia para la solución final del litigio pues, de prosperar, impedirían un pronunciamiento sobre el fondo.

Asimismo, puede constatarse que no existe en la Sentencia del Tribunal Supremo contestación expresa a tales cuestiones, y que dicha respuesta tampoco puede deducirse de otros razonamientos de la Sentencia pues ésta centró su atención de manera exclusiva en la cuestión de fondo suscitada por la Sociedad que recurrió en apelación.

Cabría plantearse si el hecho de que la Sala entre a decidir directamente sobre el fondo del asunto no puede interpretarse, precisamente, como una desestimación implícita de las cuestiones previas suscitadas por la Corporación apelada: si al órgano judicial no le pudieron pasar desapercibidas tales cuestiones: y sin embargo, se limitó a decidir sobre el fondo, cabría concluir que no las consideró relevantes. Tal planteamiento resulta no obstante, poco respetuoso no sólo con lo dispuesto en el artículo 120.3 C.E. sino, también, con el artículo 24.1 C.E. que, como antes se ha indicado, implica la obligación de los órganos judiciales de motivar sus decisiones, obligación que si bien no exige una exhaustiva 
descripción del proceso intelectual que lleva al órgano judicial a adoptar una solución determinada, ni le impone un concreto alcance o intensidad en el razonamiento empleado (SSTC 100/1987 y 109/1992), sí supone al mismo tiempo «una garantía esencial del justiciable mediante la cual sin perjuicio de la libertad del Juez en la interpretación de las normas, se pueda comprobar que la solución dada al caso es consecuencia de una exégesis racional del ordenamiento y no el fruto de la arbitrariedad" (STC 116/1986, fundamento jurídico 5..$^{\circ}$. Cuando esta respuesta razonada no se produce, ni es posible deducirla razonablemente de las circunstancias que rodean al caso concreto o de otras afirmaciones de la Sentencia, no se respetan las garantías del artículo 24.1 C.E., así se ha señalado por el Tribunal Europeo de Derechos Humanos en las Resoluciones de 9 de diciembre de 1994 antes mencionadas.

Habría que plantearse, no obstante, si, tal y como afirma el Ministerio Fiscal, el hecho de que en la Sentencia de instancia se resolviera de forma razonada sobre los motivos de inadmisibilidad del recurso permite entender que hay una aceptación implícita por parte del Tribunal Supremo de dichos razonamientos, pudiendo conocer el recurrente los motivos que han llevado al órgano judicial a desestimar sus pretensiones. En definitiva, y según este planteamiento se podría afirmar que una vez resueltas en la Sentencia de instancia determinadas cuestiones planteadas por las partes, el no tratamiento de las mismas por el órgano que resuelve el recurso de apelación -aunque tales cuestiones se hubieran reiterado en éste- no vulneraría el derecho a la tutela judicial efectiva pues, en última instancia, la parte habría obtenido ya un pronunciamiento fundado. Cabría hablar, en definitiva, de una respuesta por remisión, respuesta que este Tribunal viene considerando respetuosa con el derecho a la tutela judicial efectiva (AATC 688/1986 y 956/1988 y SSTC 174/1987, 146/1990, 27/1992, 150/1993, 11/1995, entre otras), pues "una fundamentación por remisión no deja de serlo ni de satisfacer la exigencia contenida en el derecho fundamental que se invoca».

Es cierto que, desde esta perspectiva, nada impide al Tribunal que interviene en segunda instancia hacer una remisión, incluso genérica, a los razonamientos de la Sentencia de instancia sobre alguno o algunos de los problemas suscitados en el recurso, pues, en definitiva, ello permite al justiciable conocer los motivos que están en la base de la decisión de la resolución adoptada y se satisfacen, con ello, las exigencias del artículo 24.1 C.E. Sin embargo, la conclusión debe de ser la contraria cuando, como ocurre en el presente caso, la remisión no se ha producido explícitamente, ni siquiera de forma genérica por aceptación expresa de los fundamentos de la Sentencia apelada, pues la afirmación de que la falta 
de pronunciamiento debe entenderse como una remisión implícita debe hacerse entonces sobre el terreno poco firme -y, por ello, poco acorde con la seguridad que con el Derecho se persigue- de las hipótesis o suposiciones, pues no hay forma de constatar si existió realmente una aceptación de los pronunciamientos de la Sentencia de instancia o mucho más sencillamente, un desconocimiento por el órgano judicial de alguno o algunos de los problemas suscitados. Por ello, la hipótesis de la remisión implícita no satisface las exigencias del artículo 24.1 C.E.

Estas consideraciones deben llevar en el presente caso a otorgar el amparo solicitado y a anular la Sentencia de la Sala Tercera del Tribunal Supremo al objeto de que dicte nueva Resolución en la que se pronuncie expresamente sobre las cuestiones de inadmisibilidad suscitadas por el Ayuntamiento recurrente" (vid. f.j. 91).

Fallo: Otorgar el amparo solicitado y, en consecuencia:

$1 .^{\circ}$ Reconocer al recurrente su derecho a la tutela judicial efectiva (artículo 24.1 C.E.).

$2 .^{\circ}$ Restablecerle en la integridad de su derecho fundamental y anular la Sentencia de la Sección Sexta de la Sala Tercera del Tribunal Supremo de 22 de junio de 1992.

3. Retrotraer las actuaciones al momento inmediatamente anterior a dictar Sentencia, para que la Sala Tercera del Tribunal Supremo dicte otra en la que resuelva las causas de inadmisibilidad del recurso alegadas.

(Sentencia n. ${ }^{\circ}$ 91/1995, de 19 de junio. Sala Segunda. BOE 24-71995. C. Viver Pi-Sunyer).

2. Recurso de amparo núm. 1802/92, interpuesto contra la Sentencia que la Sección Segunda de la Sala de lo Contencioso-Administrativo del Tribunal Superior de Justicia de Galicia dictó el 22 de mayo de 1992, por la que se desestimó el recurso contencioso-administrativo interpuesto contra la resolución sancionadora de 23 de octubre de 1989 del Director General de Pesca de la Junta de Galicia, confirmada en alzada por otra pronunciada el 26 de abril de 1990 por el Consejero de Pesca, Marisqueo y Acuicultura de la Junta. El recurrente en amparo imputa a la resolución judicial incongruencia omisiva al haber guardado silencio absoluto sobre la alegación principal referida a la prescripción de la infracción. El TC otorga el amparo. 
RESEÑA DE SENTENCLAS DEL TRIBUNAL CONSTITUCIONAL SOBRE LA ADMLNISTRACIÓN LOCAL...

«Dilucidado esto, conviene abordar inmediatamente después el reproche que se imputa a la Sentencia de la Sala de lo Contencioso-Administrativo por su carácter formal en principio, aun cuando contenga también resonancias sustantivas. Se trata de la congruencia como elemento interno de la decisión judicial (artículo 359 L.E.C.) y, en este caso, de una de las modalidades de su carencia total o parcial, la incongruencia ex silentio, por otro nombre omisiva. En opinión de este Tribunal Constitucional sólo se menoscaba la plenitud de la tutela judicial cuando el órgano judicial deja sin contestar las pretensiones de las partes, sometidas a su conocimiento, siempre que el silencio judicial no puede razonablemente interpretarse como una desestimación tácita, cuya motivación pueda inducirse del conjunto de los razonamientos contenidos en la resolución (SSTC 368/1993 y 91/1995). Ahora bien, para que tal tacha sea atendible en esta sede, debe comprobarse si concurren dos datos esenciales: uno, el efectivo planteamiento del problema y otro la ausencia de respuesta razonada por parte del juzgador (STC 87/1994).

Es inconcuso que se da el primero de tales elementos, cuya existencia nadie discute. Efectivamente, en la demanda del recurso contenciosoadministrativo, donde se predicaba la nulidad de los actos administrativos sancionadores adoptados por la Junta de Galicia, fueron alegadas dos causas distintas pero convergentes como fundamento de tal pretensión: una, que se había desconocido la presunción de inocencia del sancionado y, otra, que la infracción estaba prescrita. En su contestación a la demanda, la Junta de Galicia centró todo el esfuerzo argumental en demostrar la inexistencia de tal extinción de la responsabilidad, que fue puesta en juego otra vez por el demandante en el trámite de las conclusiones por escrito, sustitutivas de la vista pública. La Sentencia dio respuesta a la primera cuestión pero guardó silencio absoluto sobre la otra, silencio que ha de ser calificado como denegación de justicia y, por ello, menoscaba la efectividad de la tutela judicial (SSTC 29/1987, 8/1989, $5 / 1990$ y 52/1991), desde el momento en que una cuestión planteada y no ya pertinente sino crucial para el litigio ha recibido la callada por respuesta, sin que por otra parte pueda colegirse que haya sido tácitamente rechazada. Efectivamente, el enjuiciamiento de la prescripción, prioritario por ser una excepción que determina la extinción de la responsabilidad y, por tanto, hace imposible el ejercicio de la correspondiente potestad sancionadora de la Administración, no puede estimarse implícito en unos razonamientos cuya premisa consiste precisamente en dar por supuesta tal responsabilidad, afrontándola directamente. Se trata lisa y llanamente de un olvido, omisión no deliberada, que sin embargo enerva el pronunciamiento judicial» (f.j. 3). 
«Siendo así, como así es, aquí se alza la frontera insalvable que deslinda nuestra jurisdicción de la ordinaria. El demandante merece el amparo que pide, pero éste sólo puede llegar a la anulación de la Sentencia para que su autora, la Sala de lo Contencioso-Administrativo, pueda reconsiderar en su conjunto el planteamiento y, con ello, la cuestión omitida, dictando otra donde se le dé respuesta cumplida y coherente. Concretar por una parte las circunstancias determinantes de la prescripción, valorando los elementos de juicio existentes en el proceso y subsumir luego tal presupuesto de hecho en la norma que se considere pertinente, son operaciones que en principio se mueven en el plano de la legalidad y componen el contenido de la potestad de juzgar en que consiste la función jurisdiccional, exclusiva y excluyente, que ha de ser ejercida con total independencia por quienes son sus titulares, uno a uno, del Poder Judicial (artículo 117 C.E.). Este Tribunal Constitucional, que no es una instancia más ni ejerce funciones casacionales, cuya misión es la producción de la doctrina legal, propia del Tribunal Supremo, ha de abstenerse en principio de un juicio desde tal perspectiva, a salvo siempre la suya propia, que consiste en la salvaguardia de las garantías constitucionales» (f.j. 4).

Fallo: Otorgar el amparo solicitado y, en su virtud:

1. Reconocer el derecho del recurrente a la tutela judicial efectiva sin sufrir indefensión.

2. Declarar la nulidad de la Sentencia dictada por la Sección Segunda de la Sala de lo Contencioso-Administrativo del Tribunal Superior de Justicia de Galicia el 22 de mayo de 1992, en el recurso 706/90.

3. Restablecer al recurrente en la integridad de su derecho, retrotrayendo las actuaciones al momento inmediatamente anterior al pronunciamiento de la Sentencia para que, por el mencionado Tribunal, se dicte otra en la que dé respuesta a la alegación de prescripción de la infracción que aquél formuló.

4. Desestimar la demanda de amparo en todo lo demás.

(Sentencia $n^{\circ}$ 146/1995, de 10 de noviembre. Sala Segunda. BOE 1011-1995. R. de Mendizábal Allende).

3. Recurso de amparo núm. 1.297/1994, interpuesto por una entidad mercantil, contra el Auto de la Sala Tercera del Tribunal Supremo, de 17 de marzo de 1994, que acuerda inadmitir el recurso de casación for- 
RESEÑA DE SENTENCLAS DEL TRIBUNAL CONSTITUCIONAL SOBRE LA ADMINISTRACIÓN LOCAL...

mulado, y contra la Sentencia dictada por la Sala de lo ContenciosoAdministrativo del Tribunal Superior de Justicia de Madrid de 3 de febrero de 1993, que desestima el recurso deducido contra la Resolución del Ayuntamiento de Madrid de 21 de mayo de 1987, sobre plusvalía. El recurrente en amparo alega, respecto del Auto, que se ha vulnerado su derecho a la tutela judicial efectiva, en su vertiente de acceso a los recursos legalmente previstos, por entender que el Auto carece de toda motivación razonable y, respecto de la Sentencia, que ha resuelto la cuestión litigiosa con fundamento en la falta de pruebas de ciertos hechos, que, pese a ser declarados pertinentes, no fueron practicadas en el período probatorio. El TC deniega el amparo.

«Desde la STC 3/1983, se precisó el diferente relieve constitucional del derecho de acceso a la jurisdicción y el de acceso a los recursos legalmente establecidos, resultando éste un mero corolario de aquél en cuanto el derecho a acceder a la justicia no viene otorgado por la ley, sino por la CE, siendo distinto el enjuiciamiento que pueden recibir las normas obstaculizadoras o impeditivas del acceso a la jurisdicción o aquellas otras que limitan la admisibilidad de un recurso extraordinario contra una sentencia anterior dictada en un proceso con todas las garantías, ya que la aplicación de aquéllas puede eliminar el derecho a someter el caso a un juez, y la de las segundas solamente privaría de la revisión de la respuesta judicial ya pronunciada en la sentencia de instancia, por lo cual se habría satisfecho el núcleo esencial reconocido en el artículo 24.1 CE en tanto derecho a obtener tutela efectiva del juez ... Sobre acceso al recurso extraordinario de casación, hemos dicho que el sistema de recursos se integra en la tutela judicial con la configuración que le dé cada una de las leyes reguladoras de los diferentes órdenes jurisdiccionales, sin que exista un derecho constitucional a disponer de tales medios de impugnación, salvo en lo penal (SSTC 140/1985, $37 / 1988$ y 106/1988). Y como consecuencia de ello, el principio hermenéutico pro actione no opera con igual intensidad en la fase inicial del proceso para acceder al sistema judicial que en las sucesivas, conseguida que que una primera respuesta judicial a la pretensión, que es la sustancia medular de la tutela y su contenido esencial, sin importar que sea única o múltiple, según regulen las normas procesales el sistema de recursos» (vid. f.j. 2).

«En relación con la falta de práctica de una prueba previamente admitida, se vulnera el derecho fundamental a utilizar los medios pertinentes para la defensa cuando la omisión de la ejecución de una prueba, declarada pertinente y admitida, por causas no imputables a la parte 
recurrente produzca indefensión, pues la que prescribe la $\mathrm{CE}$ ha de ser material, por la relevancia misma de los hechos que se quisieran probar en la decisión final del pleito, ya que sólo en tal caso podrá apreciarse el menoscabo efectivo del derecho fundamental» (vid. f.j. 4)

«La Sala, al dictar la resolución impugnada, consideró y tuvo en cuenta tales índices (los índices de valores del Impuesto sobre el incremento del valor de los terrenos), que aun cuando no constaban aportados al proceso, eran conocidos y fueron aplicados por el órgano judicial en virtud del principio iura novit curia (STC 151/1994), dada su específica naturaleza juridico-normativa, afirmada tanto por la doctrina como por la jurisprudencia del TS. Ello permitió al órgano judicial contar, para la revisión de la conformidad y legalidad de la liquidación tributaria practicada por la Administración, con dichos elementos determinadores de la base imponible que se integran en la ordenanza fiscal reguladora del Impuesto, y de los cuales incluso la propia parte podía disponer, sin precisar su prueba, dada la naturaleza normativa de los índices y el público conocimiento mediante su publicación oficial (artículos 355.2 y 357.1 del texto refundido del Impuesto, de 18 de abril de 1986).

Por todo ello, ha de concluirse que en el presente caso no se ocasionó ningún perjuicio o menoscabo al derecho de defensa de la entidad mercantil demandante de amparo, toda vez que la prueba declarada pertinente, pero no practicada, resultó irrelevante en el pronunciamiento final, y ninguna incidencia tuvo en el fallo la falta de realización de la misma» (vid. f.j. 6).

Fallo: Denegar el amparo solicitado.

(Sentencia n. ${ }^{\circ}$ 110/1995, de 4 de julio. Sala Primera. BOE 3-8-1995. A. Rodríguez Bereijo).

\section{ACTIVIDAD SANCIONADORA}

1. Recurso de amparo núm. 2.273/93, promovido por un parlamentario gallego contra Resolución del Presidente del Parlamento de Galicia, de 18 de junio de 1993, por la que se confirma la decisión del Presidente de la Comisión de Modificación del Reglamento, de fecha 17 de junio de 1993, de suspender al Diputado recurrente en el ejercicio de sus derechos parlamentarios por el plazo de un mes. El TC otorga el amparo. 
RESEÑA DE SENTENCIAS DEL TRIBUNAL CONSTITUCIONAL SOBRE LA ADMINISTRACION LOCAL...

«El verdadero núcleo de la presente demanda de amparo viene constituido por una queja muy concreta: la eventual infracción del artículo 25.1 C.E. y, de forma refleja, del artículo 23 C.E., como consecuencia de la aplicación por órgano incompetente de una norma sancionadora inadecuada al supuesto de hecho que en ella ha pretendido subsumirse» (vid. f.j. 1).

«Si el Diputado fue llamado reiteradamente al orden para que dejara de hacer uso de la palabra la sanción procedente era la de impedirle asistir al resto de la Sesión (artículo 106.1), esto es, expulsarlo. Como quiera que el recurrente se negó a abandonar la Sesión, entraría en juego la previsión contenida en el artículo 106.2: uso de la fuerza e imposición de la prohibición de asistir a la siguiente Sesión, «sin perjuicio de lo establecido en el artículo 103", es decir, sin perjuicio de que el Pleno de la Cámara acuerde suspender al Diputado en su condición de tal (supuesto del artículo 103.3).

De la conjunción de los preceptos transcritos resulta que la suspensión temporal sólo puede acordarla el Pleno (artículo 103) o, excepcionalmente, el Presidente de la Cámara en el supuesto del artículo 108: promoción de desorden grave. En el presente caso, la suspensión fue acordada por el Presidente de una Comisión, órgano al que sólo corresponde la competencia sancionadora prevista en el artículo 106. Ciertamente, la sanción fue posteriormente ratificada por la Presidencia del Parlamento, pero ha de repararse en el hecho de que el Presidente de la Cámara sólo puede imponer sanciones ex artículo 108 en el mismo instante en el que se produzcan los desórdenes a que se refiere ese precepto [“(...) Si se tratase de un Diputado, el Presidente le suspenderá, además, en el acto (...)»]» (vid. f.j. 2).

«Se plantea así cuestión similar a la que motivó la concesión del amparo en la STC 136/1989: imposición extemporánea de sanción, salvo que se entienda que la Presidencia a la que se refiere el artículo 108 es tanto la de la Cámara como la de las Comisiones. Si se admite esa posibilidad, quedaría fuera de cuestión la competencia del Presidente de la Comisión para aplicar el artículo 108, pero se mantendrían, no obstante, dos dudas:

A) En primer lugar, si la existencia de una previsión normativa más específica (artículo 106) excluía la aplicación de un precepto ideado para reprimir desórdenes graves. Puede admitirse que la conducta del recurrente generó un desorden de esa especie y, por tanto, era perfectamente aplicable el artículo 108. Sin embargo, parece más razonable 
pensar que los desórdenes del artículo 108 son de entidad diversa a la del desorden que inevitablemente acompaña a la actitud de todo Diputado que se niega a dejar la palabra y a acatar una orden de expulsión de la Sesión. En otras palabras, las previsiones de los artículos 103 y 106 se refieren a supuestos que, por su anormalidad, producen sin duda un trastorno en el desarrollo de las Sesiones susceptible de ser calificado de desorden, pero parece claro que el «desorden grave» del artículo 108 lo es de otra naturaleza: manifestaciones en el recinto parlamentario, agresiones, etc.

B) En segundo término, aun cuando se admitiera que el Presidente de una Comisión puede imponer la sanción prevista en el artículo 108 y que la conducta del recurrente es incardinable en el concepto de "desorden grave" a que se refiere dicho precepto, subsiste un obstáculo para entender que era de aplicación el repetido artículo 108, a saber: en la Resolución del Presidente del Parlamento por la que se acuerda ratificar la aplicación que del artículo 108 hizo el Presidente de la Comisión en la Sesión de 17 de junio de 1993 se toman en consideración los sucesos acaecidos en la Sesión de 15 de junio de 1993. Ello supone que, admitida la competencia del Presidente de la Comisión para sancionar «en el acto» (artículo 108) la conducta observada por el Diputado recurrente en la Sesión de 17 de junio, es obvio que la inmediatez exigida por el precepto no concurría respecto de lo sucedido el 15 de junio, por lo que lo acaecido en esta última fecha no podía dar lugar a sanción ex artículo 108, sino, únicamente, a la puesta en marcha del mecanismo sancionador previsto en el artículo 103 del Reglamento.

En la medida en que la sanción ahora impugnada se fundamenta en la conducta del recurrente en ambas sesiones, puede concluirse que el artículo 108 se ha aplicado a hechos para los que no está previsto (los no verificados "en el acto" de su aplicación) y, en la medida en que lo que motivó la sanción impuesta fue la consideración conjunta de hechos "actuales", y hechos "pretéritos" es evidente que, de no haberse producido la errónea inclusión de estos últimos, la sanción procedente pudo haber sido distinta de la que efectivamente se impuso. En último término, por tanto, ha venido a conculcarse el derecho fundamental del actor $e x$ artículo 25.1 C.E., pues se le ha aplicado un precepto sancionador que, según su propio tenor, no se ha previsto para supuestos como el considerado en la Resolución sancionadora. Con ello, indirectamente, se le ha lesionado en su derecho fundamental reconocido en el artículo 23.2 C.E.» (f.j. 3). 
RESEÑA DE SENTENCIAS DEL TRIBUNAL CONSTITUCIONAL SOBRE LA ADMINISTRACION LOCAL...

Fallo: Estimar parcialmente el presente recurso de amparo y, en consecuencia:

1. Reconocer el derecho del demandante a no ser sancionado por acciones que no constituyen infracción parlamentaria subsumible en el artículo 108 del Reglamento del Parlamento de Galicia y a ejercer sus funciones como Diputado del Parlamento de Galicia.

2. Anular la Resolución del Presidente del Parlamento de Galicia de 18 de junio de 1993, por la que se ratifica la decisión adoptada por el Presidente de la Comisión de Modificación del Reglamento de 17 de junio de 1993 y anular esta última decisión.

3. Desestimar el recurso en lo demás.

(Sentencia n. ${ }^{\circ}$ 169/1995, de 20 de noviembre. Sala Segunda. BOE $28-$ 12-1995. J.D. González Campos).

\section{EXPROPLACIÓN FORZOSA}

1. Recurso de amparo núm. 1028/1993, promovido contra la Sentencia de 22 de Febrero de 1993, de la Secc. 6. ${ }^{a}$ de la Sala 3. ${ }^{a}$ del TS que, estimando el recurso de apelación interpuesto por el Abogado del Estado, revocó la dictada por la Sala de lo Contencioso-Administrativo del TSJ de la Comunidad Valenciana en asunto sobre expropiación forzosa. El demandante de amparo entiende que ha sido vulnerado el artículo 24.2 CE porque el resultado de la sentencia que ahora se impugna fue el de impedirle obtener el amparo judicial frente a la inactividad reiterada del Jurado Provincial de Expropiación Forzosa y el incumplimiento de su obligación de resolver en el plazo legalmente establecido. El TC otorga el amparo.

«El presente recurso de amparo se dirige contra la reseñada sentencia de la Sala 3..$^{a}$ del TS en la que, estimándose la causa de inadmisión invocada por el representante de la Administración apelante, se revocó la sentencia dictada en la instancia en la que se fijaba jurisdiccionalmente el justiprecio de una expropiación ante la inactividad del Jurado Provincial de Expropiación Forzosa, a quien legalmente correspondía determinar el valor del bien expropiado mediante una resolución que culmina la vía administrativa y condiciona procesalmente el acceso del titular del bien expropiado a la jurisdicción contencioso-administrativa. 
Para el TS, en la sentencia que ahora se impugna, el incumplimiento por el Jurado de Expropiación del plazo legalmente previsto para resolver acerca del justiprecio no genera un acto administrativo presunto como consecuencia de la técnica del silencio, porque tales Jurados operan ex lege de oficio, sin solicitud o petición del administrado y porque, además, «no están incardinados en la organización jerárquica de la Administración y en mérito de ello tampoco les resulta de aplicación la doctrina del silencio" (fundamento de Derecho tercero). No existiendo, por tanto, acto administrativo susceptible de impugnación jurisdiccional, el recurso contencioso-administrativo promovido por el actor debió ser inadmitido por concurrir la causa prevista en el artículo $82 \mathrm{c}$ ) LJCA.

A juicio del Abogado del Estado, la doctrina contenida en la sentencia es legal y constitucionalmente correcta por lo que no existe vulneración alguna del derecho fundamental a la tutela judicial efectiva que re-

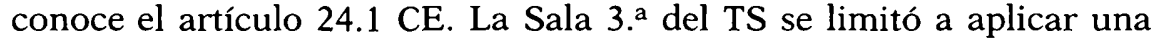
causa de inadmisión legalmente prevista, interpretándola de forma no ilógica o arbitraria. Además, añade esta representación, determinar la existencia o no de un acto administrativo es una cuestión de estricta legalidad ordinaria cuya competencia corresponde en exclusiva a los Jueces y Tribunales ex artículo $117.3 \mathrm{CE}$. Se alega, finalmente, que tampoco la denuncia de la mora ante el Jurado Provincial de Expropiación Forzosa produce un acto administrativo por silencio, sino otros efectos legalmente previstos como el devengo de interés o, en su caso, la responsabilidad disciplinaria del funcionario causante del retraso o del defecto de tramitación.

Por su parte, tanto el recurrente como el Ministerio Fiscal consideran que la doctrina de la sentencia impugnada es contraria al derecho a una tutela judicial efectiva por cuanto que, en su opinión, la inactividad del Jurado Provincial de Expropiación Forzosa y la correspondiente demora en la efectividad del derecho a la indemnización por lo expropiado, que reconoce el artículo $33.3 \mathrm{CE}$, no puede verse favorecida y premiada mediante una interpretación de la legalidad que impide la defensa judicial del administrado ante la pasividad de la Administración, creándose un ámbito exento al control jurisdiccional que contraviene el contenido medular del derecho a una tutela judicial efectiva que garantiza el artículo 24.1 CE» (f.j. 1).

«Así centrados los términos del debate, es claro desde un punto de vista material que no estamos ante un supuesto en el que el derecho pretendidamente vulnerado sea el de la tutela judicial efectiva en su vertiente de derecho de acceso a los recursos legalmente establecidos. 
Antes bien, el resultado de la sentencia que ahora se impugna fue el de denegar el acceso mismo del administrado a la jurisdicción, impidiéndosele obtener el amparo judicial frente a la inactividad reiterada del Jurado Provincial de Expropiación Forzosa y el incumplimiento de su obligación de resolver en el plazo legalmente establecido" (vid. f.j 2).

«Es indudable que las resoluciones por las que los Jurados de Expropiación fijan el justiprecio ultiman la vía administrativa y que contra las mismas "procederá tan sólo el recurso contencioso-administrativo" (artículo 35.2 LEF), por lo que merecen la consideración de «actos de la Administración Pública sujetos al Derecho Administrativo" a los efectos del artículo 1.1 LJCA. Es claro, también, que en el presente asunto el Jurado Provincial dejó transcurrir con creces el plazo para resolver, sin justificar las causas del retraso, incumpliendo una obligación legalmente impuesta (artículo 34 LEF) y causando una demora en el efectivo reconocimiento del derecho subjetivo del hoy actor a percibir una indemnización como consecuencia de la expropiación de sus bienes.

Es igualmente cierto que ante la conducta omisiva del Jurado de Expropiación el hoy actor denunció debidamente la mora, sin que esta denuncia pueda ser restrictivamente considerada, como pretende el Abogado del Estado, a los solos efectos de devengo de intereses ex artículo $56 \mathrm{LEF}$, puesto que no cabe descartar su validez como manifestación reaccional del administrado por la que se interesa que la Administración ponga remedio a su inactividad. Es más, aunque se partiera de la premisa de que el procedimiento ante el Jurado de Expropiación es un procedimiento incoado de oficio, no puede desconocerse: que de él pueden derivarse efectos favorables para el expropiado, que éste ha sido parte en el referido procedimiento y en él ha formulado una valoración de los bienes expropiados mediante la hoja de aprecio a la que no cabe negar características materiales de petición y, en fin, que en este caso el procedimiento trae causa de una previa actuación de gravamen de la Administración - que conlleva nada menos que la ocupación de la finca sin consignación previa - que produce sin duda una minoración de la esfera jurídica del particular. Por esta razón, como se declaró en el ATC 409/1988, "no es cierto que, en virtud de una interpretación formalista, un recurso contencioso-administrativo dirigido contra la eventual denegación tácita de la petición (en aquel supuesto como en el presente, a formular ante la pasividad de un Jurado de Expropiación Forzosa) hubiere de ser inadmitido por inexistencia de acto previo. Si esto ocurriera, siempre se podrá acudir de nuevo ante este Tribunal invocando el art. 24.1 CE». 
Finalmente, tampoco la admisión del recurso supone necesariamente - como pretende el Abogado del Estado- que los Tribunales de lo Contencioso-Administrativo tengan que sustituir al Jurado de Expropiación y fijar por sí el justiprecio, puesto que, sin perjuicio de que la jurisdicción no tiene por qué tener siempre un carácter exclusivamente revisor, es lo cierto que, para la satisfacción del derecho a la tutela del recurrente, les puede bastar con ponderar, en cada supuesto, las circunstancias causantes de la inactividad administrativa en relación con los perjuicios que de aquélla se puedan derivar para los derechos e intereses legítimos del administrado, reconociendo, en su caso, su derecho a que el Jurado de Expropiación resuelva en plazo, y adoptando, en el trámite de ejecucion de sentencia, las medidas necesarias para reparar esa inactividad de la Administración.

Por el contrario, en la sentencia del TS, al partirse de la idea de que la única inactividad de la Administración susceptible de revisión jurisdiccional es aquella que se puede identificar mediante una aplicación formalizada y restrictiva de la técnica del silencio administrativo, se consideró que no existía jurídicamente un acto, siquiera ficticio o tácito, de acuerdo con la legislación aplicable en ese momento que permite llegar a la vía judicial superando los efectos de la inactividad de la Administración (STC 6/1986) o, más simplemente, no consideró que el administrado estaba legalmente facultado para reaccionar frente a esa pasividad, con el inadmisible efecto, desde la óptica del derecho que reconoce el artículo $24.1 \mathrm{CE}$, de convertir la inactividad de los Jurados Provinciales de Expropiación Forzosa, en punto a la cuantificación del justiprecio, en un ámbito inmune al control judicial. Se trata, pues, como queda dicho, de una inactividad consistente en la no realización de un acto administrativo al que la Administración venía legalmente obligada, del que dependía un derecho del administrado - al cobro del justiprecio- y que traía causa de una previa actuación de gravamen de la propia Administración - una expropiación con ocupación- que había producido una minoración de la esfera jurídica del particular. Esa interpretación de la legalidad ordinaria, notoriamente desfavorable a la efectividad del acceso a la jurisdicción, conduce a una ablación del derecho fundamental del actor a la tutela judicial efectiva, al impedirle reaccionar jurisdiccionalmente frente al comportamiento pasivo de la Administración en defensa de sus derechos e intereses legitimos. La presente demanda de amparo ha de ser, en consecuencia, estimada» (vid. f.j. 4).

«Queda, no obstante, por determinar el alcance de nuestro fallo. A juicio del MF, bastará con anular la sentencia impugnada y ordenar que 
se dicte otra por la propia Sala $3 .^{a}$ del TS entrando en el fondo del asunto, para reparar la lesión del derecho a la tutela del demandante. Sin embargo, como se desprende de las actuaciones obrantes ante este Tribunal, el recurso de apelación promovido por la Abogado del Estado ante el TS versaba exclusivamente, al igual que había hecho en instancia, sobre la no aplicación por la Sala de instancia de la causa de inadmisión prevista en el artículo $82 \mathrm{c}$ ) LJCA, sin cuestionar los demás pronunciamientos contenidos en su sentencia. Siendo éste el petitum al que debemos ceñirnos, resulta en este caso improcedente la retroacción del proceso para que el TS se pronuncie de nuevo" (f.j. 5).

Fallo: Otorgar el amparo solicitado y, en consecuencia:

1. Reconocer su derecho a la tutela judicial efectiva ex artículo 24.1 CE.

2. Restablecerle en la integridad de su derecho fundamental y anular la Sentencia de la Sala 3. ${ }^{a}$ (Secc. 6. ${ }^{\mathrm{a}}$ ) del TS. de 22 de febrero 1993.

(Sentencia n. ${ }^{\circ}$ 136/1995, de 25. de septiembre. Sala Segunda. BOE 1410-1995. C. Viver Pi-Sunyer).

\section{URBANISMO}

1. Recurso de amparo núm. 773/93, promovido contra la Sentencia de la Sección Séptima de la Sala Tercera del Tribunal Supremo, de 15 de diciembre de 1992, que estimó el recurso de apelación interpuesto contra la dictada por la Sección Segunda de la Sala de lo Contencioso-Administrativo del Tribunal Superior de Justicia de Cataluña, de 30 de julio de 1990, y contra el Acuerdo del Pleno del Ayuntamiento de Barcelona, de 12 de septiembre de 1989, que ratificó la aprobación provisional acordada por la Comisión de Gobierno del 12 de julio anterior del denominado "Plan Especial de desarrollo de un Parque Urbano en el Sector Piscinas y Deportes de Barcelona", así como contra la desestimación tácita del recurso de reposición interpuesto contra dicho Acuerdo. Los recurrentes en amparo alegan la vulneración del artículo 23.1 de la CE al haberse acordado la aprobación provisional del Plan, en el que se habian introducido modificaciones sustanciales, sin acordarse nuevo trámite de información pública. El TC deniega el amparo. 
"Cuestión central en el presente recurso de amparo es la consistente en determinar si la omisión por parte del Ayuntamiento de Barcelona de la apertura de un segundo trámite de información pública antes de la aprobación provisional de un Plan Especial (obligación prevista en el artículo 130 del Reglamento de Planeamiento para el Desarrollo y Aplicación de la Ley sobre Régimen del Suelo y Ordenación Urbana para el supuesto de que se hayan introducido modificaciones que signifiquen un cambio sustancial en los criterios y soluciones del Plan inicialmente aprobado) puede traducirse no sólo en una infracción de la legalidad controlable por los Tribunales ordinarios sino también -como afirman los recurrentes - en una violación del derecho de participación directa en los asuntos públicos que garantiza el artículo 23.1 C.E.» (vid. f.j. 1).

«Para que la participación regulada en una Ley pueda considerarse como una concreta manifestación del artículo $23 \mathrm{C}$.E. es necesario que se trate de una participación política, es decir, de una manifestación de la soberanía popular, que normalmente se ejerce a través de representantes y que, excepcionalmente, puede ser directamente ejercida por el pueblo, lo que permite concluir que tales derechos se circunscriben al ámbito de la legitimación democrática directa del Estado y de las distintas entidades territoriales que lo integran, quedando fuera otros títulos participativos que derivan, bien de otros derechos fundamentales, bien de normas constitucionales de otra naturaleza, o bien, finalmente, de su reconocimiento legislativo" (vid. f.j. 3).

«Sin necesidad de entrar ahora a determinar si el trámite de información pública es o no una concreción del artículo 105 a) de la Constitllción (aunque sí conviene poner de relieve que así viene entendiéndolo el Tribunal Supremo: Sentencia Sala Cuarta de 28.10.1988, y Sentencias Sala Tercera, Sección Quinta, de 11.3.91, 9.7.91 y 23.6.94, entre otras), o a analizar si existen o no diferencias entre dicha información pública y el trámite de audiencia que prevé el precepto constitucional, sí resulta claro que el derecho de participación que se considera vulnerado no es un derecho de participación política incardinable en el artículo 23.1 C.E. Se trata de una participación en la actuación administrativa - prevista ya, por cierto, en la legislación anterior a la Constitución-, que no es tanto una manifestación del ejercicio de la soberanía popular cuanto uno de los cauces de los que en un Estado social deben disponer los ciudadanos - bien individualmente, bien a través de asociaciones u otro tipo de entidades especialmente aptas para la defensa de los denominados intereses "difusos"- para que su voz pueda ser oída en la adopción de las decisiones que les afectan. Dicho derecho, cuya relevancia no puede ser discutida, nace, sin embargo, de la Ley y tiene - con 
RESEÑA DE SENTENCIAS DEL TRIBUNAL CONSTTTUCIONAL SOBRE LA ADMINISTRACIÓN LOCAL...

los límites a que antes hemos aludido- la configuración que el legislador quiera darle; no supone, en todo caso, una participación política en sentido estricto, sino una participación -en modo alguno desdeñableen la actuación administrativa, de carácter funcional o procedimental, que garantiza tanto la corrección del procedimiento cuanto los derechos e intereses legítimos de los ciudadanos. El hecho mismo de que muchas de estas formas de participación se articulen, como se ha dicho, a través de entidades de base asociativa o corporativa pone de relieve su diferente naturaleza respecto de la participación política garantizada por el artículo 23 C.E.; ésta, según tiene declarado este Tribunal, es reconocida primordialmente a los ciudadanos - «nuti cives»- y no en favor de cualesquiera categorías de personas (profesionalmente delimitadas, por ejemplo) (SSTC 12/1993 y 80/1994, y ATC 942/1985). Este hecho manifiesta, igualmente, que no estamos ante cauces articulados para conocer la voluntad de la generalidad de los ciudadanos - en los distintos ámbitos en que territorialmente se articula el Estado- precisamente en lo que tiene de general, sino más bien para oír, en la mayor parte de los casos, la voz de intereses sectoriales de indole económica, profesional, etc. Se trata de manifestaciones que no son propiamente encuadrables ni en las formas de democracia representativa ni en las de democracia directa, incardinándose más bien en un "tertium genus" que se ha denominado democracia participativa.

Es cierto que a través del trámite de información pública se dota de cierta legitimación popular al Plan aprobado - aunque tampoco puede olvidarse que en el presente caso la legitimidad democrática le viene dada por haber sido aprobado por un Ayuntamiento elegido democráticamente-; pero, su finalidad no es realizar un llamamiento al electorado para que ratifique una decisión previamente adoptada (ni para que determine el sentido de la que haya de adoptarse), sino, más bien, instar a quienes tengan interés o lo deseen a expresar sus opiniones para que sirvan de fuente de información de la Administración y puedan favorecer así el acierto y oportunidad de la medida que se vaya a adoptar, así como establecer un cauce para la defensa de los intereses individuales o colectivos de los potencialmente afectados. Se trata de un llamamiento a las personas o colectivos interesados al objeto de que puedan intervenir en el procedimiento de adopción de acuerdos. Evidentemente este último dato no quita relevancia a estas formas de participación que, por otra parte, se han visto reforzadas por el mandato contenido en el artículo 9.2 C.E. Una vez establecidas, no son disponibles para los poderes públicos, pudiendo incluso viciar de nulidad las disposiciones adoptadas con infracción de las mismas. Sin embargo, no resultan reconducibles al artículo 23.1 C.E., por lo que no gozan de la protección 
especial del procedimiento preferente y sumario y del recurso de amparo a que se refiere el artículo 53.2 C.E.

En consecuencia, la infracción que se denuncia en la presente demanda de amparo, aunque se hubiera efectivamente producido, no podría traducirse en una vulneración del artículo 23.1 C.E., por lo que procede la desestimación del recurso" (vid. f.j. 6).

Fallo: Desestimar la presente demanda de amparo.

(Sentencia n. $.^{\circ} 119 / 1995$, de 17 de julio. Sala Segunda. BOE 22-81995. T. S. Vives Antón).

\section{DERECHO PÚBLICO DE LA ECONOMÍA}

\section{A) Telecomunicaciones}

1. Recurso de amparo núm. 2.679/93, interpuesto contra la Resolución de la Dirección General de Telecomunicaciones, de 23 de mayo de 1989, que acordó la incoación de expediente sancionador y precinto provisional de las instalaciones y del equipo transmisor de televisión local TV-5 en Alcalá de Guadaira (Sevilla), así como contra la Sentencia del Tribunal Supremo de 10 de junio de 1993, y contra la Sentencia de la Sala de lo Contencioso-Administrativo de la Audiencia Nacional de 23 de noviembre de 1990, que desestima el recurso seguido por el cauce procesal de la Ley 62/1978, contra la mencionada Resolución. El núcleo de Ia presente demanda de amparo viene integrado por la alegación de vulneración de los derechos fundamentales a la libertad de expresión y de comunicar información [artículos. 20.1 a) y d) C.E.] como consecuencia de la resolución administrativa disponiendo la incoación de expediente sancionador y la adopción de la medida cautelar de precintado de los equipos emisores de una estación de televisión local por ondas; sostiene el recurrente en amparo que, de los citados preceptos constitucionales se deriva un derecho fundamental de los ciudadanos a emitir en la citada modalidad de televisión de cobertura local y por ondas, derecho cuya vulneración se imputa, en último término, a la Ley 10/1988, reguladora de la televisión privada; en los términos de la demanda, la Ley sería inconstitucional tanto por carecer del rango de ley orgánica como por no regular la televisión privada de cobertura local. El TC deniega el amparo.

"No resulta necesario a efectos de su respuesta el determinar ahora si la Constitución incorpora un derecho fundamental a emitir, siempre 
en el marco de la imprescindible regulación legal, en un ámbito local a través precisamente del especifico soporte de las ondas hertzianas. Por medio de la STC 31/1994, y las que le han seguido, este Tribunal, obviando la pasividad del legislador, ha venido a posibilitar un contenido mínimo, en el sentido de la STC 15/1992, de las libertades de expresión y comunicación, incorporando un derecho a la televisión como instrumento (derecho de creación de medios) en el específico ámbito de las colectividades locales, reconociendo directamente, ex Constitucione, y como remedio de urgencia, el derecho a operar en este ámbito por el concreto medio del cable, teniendo en cuenta la «escasa complejidad técnica» de su regulación y la especificidad de un soporte, se añade, que no supone el agotamiento de un medio escaso.

De este modo, y teniendo en cuenta que nuestro ordenamiento no prevé específicos pronunciamientos de inconstitucionalidad por omisión, el Tribunal se ha visto impulsado a abrir un contenido mínimo, a la espera del correspondiente desarrollo legislativo, al instrumento de la televisión en el ámbito de la sociabilidad local. Esta situación, que desde la Constitución sólo podemos considerar como interina, y teniendo en cuenta que no puede ser tarea de este Tribunal la ordenación de frecuencias y potencias, conduce a que, en relación con la televisión local difundida por medio de ondas, debamos desestimar la pretensión del demandante de que declaremos la nulidad de la medida administrativa de suspensión de las emisiones de televisión por dichas ondas hertzianas que venía efectuando, sirviéndose de frecuencias y potencias autoatribuidas, en la localidad de Alcalá de Guadaira. En efecto las limitaciones técnicas que impone la utilización del espacio radioeléctrico por parte de un numero en principio ilimitado de usuarios hace indispensable la previa regulación del medio, la cual sólo puede ser llevada a cabo por el legislador. En este sentido, la situación abierta desde nuestra STC 31/1994 permite la existencia de emisoras de televisión privada en el ámbito local, con el consiguiente despliegue de las libertades de expresión y comunicación por medio de la televisión en la escala local en un contexto, necesariamente muy provisional, de ausencia de regulación. La solución, sin embargo, patrocinada por el Ministerio Fiscal, consistente en incardinar la televisión por ondas hertzianas en esta situación provisional, implicaría, dándose un paso más en absoluto intrascendente, precondicionar, por así decir, el innegable ámbito propio de la libertad de configuración del legislador, con el coste, además, nunca despreciable, de consentir conductas ciudadanas que, más allá de las estrictas exigencias de la efectividad de la libertades públicas, se sitúen al margen de las disposiciones legales, con la consiguiente debilitación de la seguridad jurídica» (vid. f.j. 7). 
Fallo: Desestimar el presente recurso de amparo.

(Sentencia n. ${ }^{\circ} 88 / 1995$, de 6 de junio. Sala Primera. BOE 8-7-1995. P. Cruz Villalón. Voto particular que formula M. Jiménez de Parga y Cabrera, al que se adhiere V. Gimeno Sendra).

\section{B) Agricultura: denominaciones de origen}

1. Conflicto positivo de competencia núm. 1170/88, planteado por el Consejo Ejecutivo de la Generalidad de Cataluña frente al Real Decreto 157/1988, de 22 de febrero, por el que se establece la normativa a que deben ajustarse las denominaciones de origen y las denominaciones de origen calificadas de vinos y sus respectivos reglamentos. El TC declara que el Real Decreto discutido, con la sola salvedad de su disposición adicional, no es de aplicación directa en Cataluña, puesto que el Estado no posee, según el artículo 12.1.5 del Estatuto de Autonomía, facultad para dictar en dicha Comunidad Autónoma normas básicas en la sección de materia que suponen las denominaciones de origen de vinos.

«Este carácter del Decreto como regulador de normas básicas en la materia no puede constitucionalmente negarse en virtud de las competencias que el Estado ostenta en el territorio de aquellas Comunidades Autónomas que únicamente asumieron potestades de desarrollo normativo y ejecución, así como en aquellas otras que sólo poseen facultades de ejecución, entendidas en el amplio modo expuesto en la STC 209/1989, puesto que en ellas el Estado posee, incluso, una más amplia potestad normativa. Pero no puede sostenerse lo mismo respecto de $\mathrm{Ca}$ taluña donde la Generalidad ostenta, en virtud del artículo 12.1.5 de su Estatuto, una competencia exclusiva y de origen residual en la materia. Así, ya se reconoció en la STC 11/1986, que la competencia «exclusiva en colaboración con el Estado" no supone una competencia compartida que permita al Estado dictar normas básicas, doctrina constitucional que el presente Decreto, manifiestamente incumple.

Del mismo modo, la segunda justificación que se aporta en la Exposición de Motivos tampoco puede ser aceptada, puesto que la vigencia de los Reglamentos 822 y 823/1987 del Consejo de la CEE no permite atribuir al Estado unas competencias que no le otorga el bloque de la constitucionalidad dentro del ordenamiento interno y, en concreto, en la sección de materia que suponen las denominaciones de origen de 
RESEÑA DE SENTENCLAS'́dEL TRIBUNAL CONSTITUCIONAL SOBRE LA ADMINISTRACIÓN LOCAL...

vinos. En efecto, como es sabido, de conformidad con nuestra reiterada jurisprudencia, la necesidad de asumir el desarrollo y la ejecución del Derecho comunitario o de dar cumplimiento al mismo no permite alterar las reglas constitucionales de distribución de competencias (STC 252/1988, 76/1991, 115/1991, 236/1991, 79/1992...).

Una tercera hipotética justificación debe ser también analizada. Cabe preguntarse si el Estado, al amparo de su función de defensa de los Reglamentos y en el ejercicio de sus potestades de ratificación, puede dictar normas generales que resulten de obligado cumplimiento para las Comunidades Autónomas con competencia exclusiva. La respuesta debe ser necesariamente negativa en todo lo referente a la ordenación sustantiva y desde el punto de vista de la referida potestad de ratificación, puesto que por esta vía indirecta acabarían por uniformarse las competencias de las Comunidades Autónomas calificadas como exclusivas en sus respectivos Estatutos con las que no poseen tal carácter, igualmente en virtud de la asunción estatutaria; y, en definitiva, todo ello redundaría en un ilícito menoscabo de las competencias normativas de aquéllas. Pero, sobre todo, los contenidos del Decreto impugnado no se corresponden con unas normas que realmente preserven los cometidos que el Estado realiza en la defensa de los Reglamentos de las denominaciones de origen, finalidad a la que la ratificación responde, sino que atienden a unos contenidos mínimos homogeneizadores típicos de la estructura de unas normas básicas en la ordenación de una materia, que, como se ha reiterado, son impropias de una competencia exclusiva.

El Estado puede, sin duda, dictar normas válidas - con carácter básico o pleno según corresponda - allí donde las Comunidades Autónomas no tengan la competencia exclusiva. $\mathrm{E}$ igualmente puede ordenar las denominaciones de origen que abarquen el territorio de varias Comunidades Autónomas, una actuación que lógicamente sólo pueden efectuar los órganos generales del Estado. Así el propio Decreto de traspasos a Cataluña, en su Anexo, apartado B.2], letra e] dispone que en los Consejos Reguladores de Denominaciones Específicas y Denominaciones de Origen "cuyo ámbito comprenda también parte del territorio ajeno a la jurisdicción de la Generalidad de Cataluña», estará representada ésta "de acuerdo con la normativa que se establezca»; una normativa que por razones territoriales sólo puede en esos casos dictar el Estado; y es sabido que, en la realidad, no son inexistentes las denominaciones de origen de vinos que abarquen varias Comunidades Autónomas como, v. gr., ocurre con la denominación "Cava» (Órdenes de 14 de noviembre de 1991 y 9 de julio de 1992). Pero el Estado no 
puede utilizar su facultad de ratificación de los Reglamentos, a los estrictos efectos de asumir su defensa en los ámbitos nacional e internacional, para condicionar su aprobación definitiva por Comunidades Autónomas que, como la Generalidad, poseen competencia exclusiva. La filosofía de la colaboración obliga a pensar aquí que la intervención del Estado debe ser necesariamente subsidiaria del ejercicio autonómico de las competencias, en este caso normativas, y no puede llegar hasta su sustitución donde no resulte enteramente imprescindible, y nada se arguye a este respecto que demuestre el carácter indefectible de la intervención del Estado mediante normas.

La amplia regulación de detalle que contempla, sustancialmente, el Reglamento 823/1987 del Consejo de la CEE, fija un nuevo marco legal que, ciertamente, permite un desarrollo dentro de cada Estado miembro, pero dicho desarrollo normativo debe corresponder al ente territorial que tiene constitucionalmente una competencia exclusiva y residual para la aprobación de denominaciones de origen en su ámbito territorial: la Generalidad de Cataluña.

Por lo demás, nada se dice en la contestación a la demanda - ni menos aún se advierte- respecto de una supuesta afectación de la ordenación general de la economía (artículo 149.1.13 de la Constitución) por la normativa controvertida, en cuanto límite expreso a la asunción estatutaria de competencias en la materia. La finalidad perseguida por las normas objeto de conflicto está en condicionar y armonizar los contenidos mínimos de los Reglamentos de las denominaciones de origen, y aunque todo ello tiene obviamente conexión con una actividad económica, este grado reflejo de relación no permite extender de forma excesiva la cláusula constitucional mencionada hasta enmarcar cualquier acción sobre este sector de naturaleza económica, pues, de ser así, se vaciaría de contenido una materia y un título competencial más específico. Según se dice acertadamente en la demanda, la facultad de fijar las bases y coordinar la planificación general de la actividad económica no puede ser confundida con la potestad general de dictar bases en materia de denominaciones de origen allí donde el Estado no posea esta competencia, si bien es claro que «el Estado puede operar sobre el sector vitícola haciendo uso de su competencia para proceder a la ordenación general de la economía (artículo 149.1.13 C.E.), pero ello siempre que no vacíe de contenido las competencias de la Comunidad Autónoma sobre la viticultura» (STC 186/1988, fundamento jurídico 6..$^{\circ}$ ).

Sin embargo, no es esta competencia la que ha sido ejercida aquí. Los artículos 2 a 16 del Decreto impugnado aparecen en el Capítulo Se- 
RESEÑA DE SENTENCLAS DEL TRIBUNAL CONSTITUCIONAL SOBRE LA ADMINISTRACIÓN LOCAL...

gundo del mismo, bajo la rúbrica "denominaciones de origen» y los artículos 17 a 21, en el Capítulo Tercero, bajo la rúbrica «denominaciones de origen cualificadas». Por consiguiente, con independencia de su contenido, es claro que no representan normas básicas de planificación general de la actividad económica en el sector, sino reglas específicas destinadas exclusivamente a regular las bases a las que han de ajustarse las denominaciones de origen y que, por lo tanto, no pueden ser de aplicación a las Comunidades Autónomas que hayan asumido la competencia exclusiva sobre esta particular materia.

Todo ello, en fin, sin perjuicio de la insuficiencia técnica que, desde una perspectiva formal y de seguridad jurídica, aqueja al Real Decreto en conflicto en cuanto normativa básica, puesto que, además de ser una norma de rango infralegal, tan sólo alude - de forma indiferenciada y sin matices- en su Exposición de Motivos, no en su articulado, al carácter básico del Reglamento, sin invocar, por lo demás, título competencial alguno en favor del Estado que así lo legitime.

Hay que concluir, en suma, que, sin perjuicio de su hipotética supletoriedad, el Decreto discutido no es de aplicación directa en Cataluña, puesto que el Estado no posee, según el artículo 12.1.5 del Estatuto de Autonomía, facultad para dictar en dicha Comunidad Autónoma normas básicas en la sección de materia que suponen las denominaciones de origen de vinos.

Fallo: Declarar que, con la sola salvedad de su Disposición adicional, el Real Decreto 157/1988, de 22 de febrero, no es de aplicación directa en Cataluña.

(Sentencia n. ${ }^{\circ} 112 / 1995$, de 6 de julio. Pleno. BOE 3-8-1995. V. Gimeno Sendra).

\section{ESPACIOS NATURALES Y MEDIO AMBIENTE}

1. Recursos de inconstitucionalidad acumulados núms. 1.220/89, $1.232 / 89,1.239 / 89,1.239 / 89,1.260 / 89$ y 1.268/89 promovidos, respectivamente, por el Gobierno Vasco, la Junta de Andalucía, el Gobierno de Canarias, la Generalidad de Cataluña, la Junta de Galicia y el Parlamento de Cataluña, contra la Ley 4/1989, de 27 de marzo, de Conservación de los Espacios Naturales y de la Flora y Fauna Silvestres; conflictos positivos de competencia, asimismo acumulados, 95/90, 163/90,170/90, 172/90y 209/90, promovidos, respectivamente, por la 
Comunidad Autónoma de Castilla y León, el Gobierno Vasco, el Consejo de Gobierno de la Diputación General de Aragón, el Consejo Ejecutivo de la Generalidad de Cataluña, y el Consejo de Gobierno de las Islas Baleares, contra el Real Decreto 1.095/1989, de 8 de septiembre, por el que se declaran las especies objeto de caza y pesca y se establecen normas para su protección; conflicto positivo de competencia núm. 162/90 promovido por el Gobierno Vasco, contra el Real Decreto 1.118/1989, de 15 de septiembre, por el que se declaran las especies objeto de caza y pesca comercializables; conflicto positivo de competencia 210/90, interpuesto por la Diputación Regional de Cantabria contra los dos Reales Decretos antes mencionados; y conflicto positivo de competencias 1.938/90, promovido por el Consejo Ejecutivo de la Generalidad de Cataluña contra el Real Decreto 439/1990; de 30 de marzo por el que se regula el Catálogo Nacional de Especies Amenazadas. El TC estima parcialmente estos recursos.

«Se dan cita en esta Sentencia seis recursos de inconstitucionalidad, cuyo objeto común es la Ley $4 / 1989$ y ocho conflictos de competencia positivos con motivo de los Reales Decretos 1.095/1989 1.118/1989 y 439/1990, promovidos unos y otros por las Comunidades Autónomas de Andalucía, Aragón, Baleares, Canarias, Cantabria, Cataluña, Castilla y León y el País Vasco. El objeto principal, aunque no único, lo componen una serie de preceptos de la Ley 4/1989, y de las normas reglamentarias dictadas para su desarrollo, a muchos de los cuales se niega su carácter básico. El rigor de los conceptos conduce a la conclusión de que, aun cuando no siempre hayan sido impugnadas explícitamente, las dianas inmediatas de los reproches son las Disposiciones adicionales donde se incluye tal calificación si bien para comprobar su idoneidad constitucional uno por uno, caso por caso, haya que poner en la balanza cada artículo de los enumerados en ellas. La interrelación del artículo 1 de la Ley y su disposición adicional quinta (más las otras que se dirá) se ramifica a los preceptos concretos. En definitiva, por mandato de aquélla, son normas basicas los artículos 1, 2, 4, 5, 6, 8 al 19, 21 al 31 y 33 al 41, así como las Disposiciones adicionales primera, segunda, cuarta y quinta, con la transitoria segunda. A este elenco resulta necesario añadirle la Disposición adicional sexta, no incluida en la anterior y, en cambio debe ser extraído el artículo 2, que nadie impugna. La misma operación de suma pero sin resta le conviene a la Disposición adicional primera del Real Decreto 1.095/1989, donde se dice que «tendrán el carácter de normativa básica estatal» los artículos 1.1, 3.1 y 4.2, más la adicional segunda, aun cuando también se pongan en tela de juicio el párrafo primero del artículo 4 , así como los tres siguientes $(5,6$ y 7$)$ e incluso todos 
salvo el 2, el 4.4, la Disposición derogatoria y las finales, según propone Aragón. En el caso del Real Decreto 1.118/1989, cuya Disposición adicional cuarta considera básicos sus artículos $1,2.1$ y 2 y 4 queda fuera del debate ese párrafo segundo. Finalmente está en entredicho el entero Real Decreto 439/1990, cuya lacónica norma al respecto anuncia que «se dicta al amparo de lo dispuesto en el artículo 149.1,23 de la Constitución»» (vid. f.j. 1).

«El carácter complejo y polifacético que tienen las cuestiones relativas al medio ambiente determina precisamente que afecte a los más variados sectores del ordenamiento jurídico (STC 64/1982) y provoca una correlativa complejidad en el reparto de competencias entre el Estado y las Comunidades Autónomas. Por eso mismo, el medio ambiente da lugar a unas competencias, tanto estatales como autonómicas, con un carácter metafóricamente "transversal" por incidir en otras materias incluidas también, cada una a su manera, en el esquema constitucional de competencias (artículo 148.1. ${ }^{a}, 3 .^{a}, 7 .^{a}, 8 .^{a}, 10 .^{a}$ y 11. ${ }^{a} \mathrm{CE}$ ) en cuanto tales materias tienen como objeto los elementos integrantes del medio (las aguas, la atmósfera, la fauna y la flora, los minerales) o ciertas actividades humanas sobre ellos (agricultura, industria, minería, urbanismo, transportes) que a su vez generan agresiones al ambiente o riesgos potenciales para él. Es claro que la transversalidad predicada no puede justificar su "vis expansiva", ya que en esta materia no se encuadra cualquier tipo de actividad relativa a esos recursos naturales, sino sólo la que directamente tienda a su preservación, conservación o mejora. Como ya dijimos respecto de las aguas en la STC $227 / 1988$ y más precisamente en la STC 144/1985, los recursos naturales son soportes físicos de una pluralidad de actuaciones públicas y privadas en relación a los cuales la Constitución y los Estatutos han atribuido diversas competencias. En tal sentido, hemos reconocido en más de una ocasión que un ámbito físico determinado no impide necesariamente que se ejerzan otras competencias en el espacio (SSTC 77/1982 y 103/1989), pudiendo pues, coexistir títulos competenciales diversos. Así, junto al medio ambiente los de ordenación del territorio y urbanismo, agricultura y ganadería, montes y aprovechamientos forestales, o hidráulicos, caza y pesca o comercio interior entre otros. Ello significa, además, que sobre una misma superficie o espacio natural pueden actuar distintas Administraciones públicas para diferentes funciones o competencias, con la inexorable necesidad de colaboración (SSTC 227/1988 y 103/1989) y, por supuesto, coordinación. No sólo hay que identificar cada materia, pues una misma Ley o disposición puede albergar varias (SSTC 32/1983 y 103/1989), sino que resulta inevitable a continuación determinar, en cada caso, el título competencial predominante por su vinculación di- 
recta e inmediata, en virtud del principio de especificidad, operando así con dos criterios; el objetivo y el teleológico, mediante la calificación del contenido material de cada precepto y la averiguación de su finalidad (SSTC 15/1989, 153/1989 y 170/1989), sin que en ningún caso pueda llegarse al vaciamiento de las competencias de las Comunidades Autónomas según sus Estatutos (STC 125/1984)» (vid. f.j. 3).

Fallo: $1 .^{\circ}$ Declarar la nulidad de la Disposicion adicional quinta que contiene la Ley 4/1989, de 27 de marzo, de Conservación de los Espacios Naturales y de la Flora y Fauna Silvestre, en cuanto considera básicos sus artículos 21.3 y $4 ; 22.1$ en la medida en que atribuye exclusivamente al Estado la gestión de los Parques Nacionales; y 35.1 y 2.

2. Declarar la nulidad de la Disposición adicional primera del Real Decreto 1.095/1989, de 8 de septiembre, sobre declaración de especies que pueden ser objeto de caza y pesca con normas para su protección, en cuanto considera básicos los artículos 1.1, 3.1 y 4.2, y de la Disposición adicional segunda correspondiendo las competencias controvertidas a las Comunidades Autónomas de Aragón, Cantabria, Castilla y León, Cataluña, las Islas Baleares y del País Vasco.

3. Desestimar en lo demás los recursos de inconstitucionalidad y los conflictos positivos de competencia, acumulados en este proceso.

(Sentencia n. ${ }^{\circ}$ 102/1995, de 26 de junio. Pleno. BOE 31-7-1995. R. de Mendizábal Allende. Voto particular formulado por R. de Mendizábal Allende).

2. Recurso de inconstitucionalidad núm. 2.145/89, interpuesto por el Gobierno de la Nación contra los artículos 23.2 b), 23.2 c), 27, 28.4 y 29.1 de la Ley del Parlamento Vasco 5/1989, de 6 de julio, de Protección y Ordenación de la Reserva de la Biosfera de Urdaibai, por considerar que no respetan el orden constitucional de competencias, $y$, en concreto, por considerarlos contrarios a los artículos 10.3 y 39 de la Ley 4/1989, de 27 de marzo, de conservación de los Espacios Naturales y de la Flora y Fauna Silvestres, que tienen carácter básico. El TC desestima el recurso.

«Se impugnan en el presente recurso de inconstitucionalidad los artículos $23.2 \mathrm{~b}$ ), en cuanto al inciso "sesenta días naturales»; $23.2 \mathrm{c}$ ) párrafo $2 .^{\circ}$, inciso «seis meses»; 27 por imprevisión de infracciones menos 
RESEÑA DE SENTENCLAS DEL TRIBUNAL CONSTITUCIONAL SOBRE LA ADMINISTRACIÓN LOCAL..

graves; 28.4 por imprevisión de sanciones para las infracciones menos graves, de la Ley del Parlamento Vasco 5/1989, de 6 de julio, de Protección y Ordenación de la Reserva de la Biosfera de Urdaibai, por considerar que no respetan el orden constitucional de competencias y, en concreto, por considerarlos contrarios a los artículos 10.3 y 39 de la Ley 4/1989, de 27 de marzo, de Conservación de los Espacios Naturales y de la Flora y Fauna Silvestres (L.C.E.N.), que según su Disposición adicional quinta tienen carácter básico. El primero de los preceptos impugnados —el artículo 23.2 apartados b) y c) — modifica los plazos que para el ejercicio de los derechos de tanteo y retracto establece el artículo 10.3 de la Ley estatal; el artículo 27, modifica la escala de sanciones prevista en el artículo 39 de dicha Ley y, por su conexión con el artículo 27, se impugnan los artículo 28.4 y 29.1 de la Ley autonómica» (f.j.l).

"Se impugnan, en primer lugar, las letras b) y c) del apartado $2 .^{\circ}$ del artículo 23 de la Ley vasca. Este artículo establece unos derechos de tanteo y retracto en tadas las transmisiones onerosas de bienes y derechos relativos a los terrenos ubicados en determinadas zonas de la Reserva, que podrán ser ejercidos, por este orden, por la Administración de la Comunidad Autónoma, por la Diputación Foral de Bizkaia o por los Ayuntamientos afectados. Hasta aquí el precepto se hace eco de lo dispuesto en el artículo 10.3 L.C.E.N. según el cual «la declaración de un espacio como protegido lleva aparejada (...) la facultad de la Administración competente para el ejercicio de los derechos de tanteo y retracto, en las transmisiones onerosas intervivos de terrenos situados en el interior del mismo". Sin embargo, la Ley vasca establece para el ejercicio de los derechos de tanteo y retracto unos plazos de sesenta días naturales [artículo $23.2 \mathrm{~b}$ )] y de seis meses artículo $23.2 \mathrm{c}$ )], respectivamente, mientras que en el artículo 10.3 de la Ley estatal los plazos son de tres meses y un año (...).

En el presente caso, es evidente que la fijación de unos determinados plazos para el ejercicio de unos concretos derechos de tanteo y retracto en unas zonas muy concretas del territorio nacional, como son los espacios naturales protegidos, no puede ampararse en la habilitación competencial que supone el artículo 149.1.1 C.E. Y, en consecuencia, los apartados b) y c) del artículo 23.2 de la Ley de Protección y Ordenación de la Reserva de la Biosfera de Urdaibai no vulneran, desde esta perspectiva, el orden constitucional de competencias» (vid. f.j. 5).

"Descartada la infracción del artículo 149.1.1 C.E. debemos examinar los preceptos impugnados desde la óptica del artículo 149.1.23 C.E., desde el que, por otra parte, se construye el núcleo principal de la argumentación del Abogado del Estado (...). 
B) La relación entre la legislación estatal básica y la legislación autonómica de desarrollo en materia de medio ambiente, en general, y en cuanto al establecimiento de derechos preferentes, en concreto, debe ser examinada desde una doble perspectiva: desde la finalidad perseguida con dicha legislación que, como se ha dicho, no es tanto la uniformidad como el establecimiento de mínimos de protección, y desde la exigencia de que el legislador estatal no llegue a tal grado de detalle que no permita desarrollo legislativo alguno de las Comunidades Autónomas con competencia en materia de medio ambiente, vaciándolas así de contenido (STC 102/1995). Pues bien, en atención a dichos criterios ha de entenderse, en lo que aquí importa, que lo básico en la ordenación estatal es el establecimiento de un derecho de tanteo y retracto en favor de las Administraciones Públicas, la garantía de un conocimiento fehaciente por dichas Administraciones de las transmisiones inter vivos de terrenos situados en el interior de un espacio protegido y la determinación de unos plazos para el ejercicio de los derechos de tanteo y retracto que permitan asegurar una eficaz protección del espacio por los Entes competentes. Por lo que ha de admitirse que la competencia basica del Estado en materia de protección del medio ambiente no impide que las Comunidades Autónomas determinen la concreta duración de dichos plazos siempre que ésta suponga una protección suficiente que no reduzca la eficacia de la medida en relación con el espacio natural al que se aplica.

Ahora bien, ello no ocurre en el presente caso, pues los plazos establecidos por el legislador vasco son lo suficientemente amplios como para permitir que realmente puedan ejercitarse los derechos de tanteo y retracto. A mayor abundamiento, no puede desconocerse que la separación de la Ley estatal en este punto se justifica por el representante del Parlamento Vasco en las peculiaridades de la Reserva de la Biosfera de Urdaibai que, como antes se ha recordado, han llevado al legislador de aquella Comunidad a crear. al amparo de lo dispuesto en el artículo 212 L.C.E.N., una figura específica, distinta de las previstas en el artículo 12 de la.misma Ley. Entre esas peculiaridades - y tal y como se recuerda en la Exposición de Motivos de la Ley-está el hecho de que en la zona protegida se encuentran numerosos núcleos urbanos de población, con un importante desarrollo industrial y turístico, por lo que es necesario «armonizar el desarrollo de esta zona con la conservación de nuestro patrimonio y recursos naturales» (vid. f.j. 6).

«Se.impugnan también por el Abogado del Estado los artículos 27, 28.4 y 29.1 de la Ley de Protección y Ordenación de la Reserva de la Biosfera de Urdaibai. El primero de ellos establece los tipos de infrac- 
ción, que se clasifican en muy graves, graves y leves; el segundo fija los órganos competentes para imponer las sanciones y sus cuantías mínimas y máximas, y el tercero se refiere a sus plazos de prescripción. El fundamento último de la impugnación es la exclusión que en estos preceptos se hace de la categoría de sanciones " menos graves «, lo que, se afirma, infringe el artículo 39.1 L.C.E.N., precepto declarado básico y según el cual «las infracciones serán calificadas de leves, menos graves, graves y muy graves». Para el representante estatal la Ley vasca ha alterado el referido régimen sancionador sin razón que lo justifique $\mathrm{y}$, por ello, resulta en estos concretos extremos inconstitucional y nula» (vid. f.j. 7).

"Es indudable que las sanciones son un instrumento eficaz para garantizar los deberes que, para la protección de los espacios naturales y de su flora y fauna, el legislador puede establecer. Pero dicha finalidad protectora se consigue con la fijación de los tipos de ilícitos, de la especificación de la gravedad de algunos de ellos, de las cuantías mínimas de las sanciones, etc., pero no con el simple establecimiento de una gradación que sólo al legislador autonómico le corresponde posteriormente llenar de sentido. Por ello, la creación de la referida escala con un pretendido carácter básico no puede justificarse desde la necesidad de establecer unos mínimos de protección y sólo puede explicarse, bien desde la perspectiva del principio de proporcionalidad (STC 102/1995, fundamento jurídico 32), bien desde el deseo de establecer unos tipos de sanciones uniformes en todo el territorio nacional. Sin embargo, ninguna de esas finalidades está cubierta por el artículo 149.1.23 C.E. La primera, porque este precepto no es título habilitante que permita al Estado establecer una escala que garantice el principio de proporcionalidad de las sanciones, principio que viene garantizado directamente por otros preceptos de la Constitución que, evidentemente, vinculan al legislador estatal y al autonómico. La segunda, porque, como hemos recordado, la legislación básica no cumple en este caso una función de uniformidad relativa. Por ello, los preceptos impugnados, aunque se apartan de la Ley estatal, no resultan contrarios al artículo 149.1.23 C.E. Este precepto se habría infringido si se hubieran suprimido las faltas graves, pues la Ley estatal establece tres tipos de infracciones que, en todo caso, se considerarán infracciones muy graves (artículo 39.23. Esta norma ha sido declarada básica por el legislador y tal carácter ha sido confirmado por la STC 102/1995, pues efectivamente establece una protección mínima que debe ser común a todo el territorio nacional; por ello, si el legislador vasco hubiera suprimido las infracciones muy graves, o hubiera rebajado sensiblemente la cuantía de la sanción correspondiente, se habría dejado sin efecto la norma estatal. Sin embargo, la 
escala establecida por el Estado ha sido respetada en este concreto extremo" (vid. f.j. 8).

«Descartada la violación del artículo 149.1.23 C.E., debemos examinar la validez de los artículos impugnados desde la perspectiva del art. 149.1.1 C.E. pues, como antes se ha señalado, las Comunidades Autónomas, al aprobar normas sancionadoras, no pueden introducir divergencias irrazonables y desproporcionadas al fin perseguido respecto del régimen jurídico aplicable en otras partes del territorio nacional (SSTC $87 / 1985,48 / 1988,136 / 1991$ y $108 / 1993$, entre otras).

En el presente caso, la legislación estatal (artículo 39.1 L.C.E.N.) establece cuatro categorías de infracciones a las que corresponden las siguientes sanciones: leves, multa de 10.000 a 100.000 pesetas; menos graves, multa de 100.001 pesetas a 1.000 .000 de pesetas; graves, multa de 1.000.001 a 10.000.000 de pesetas; muy graves, multa de 10.000.001 a 50.000.000 de pesetas. Por su parte, la Ley vasca establece la siguiente escala (artículos 27 y 28.4): leves, multa hasta 250.000 pesetas; graves, multa de 250.001 a 15.000 .000 de pesetas; muy graves, multa de 15.000.001 a 50.000.000 de pesetas. Como puede apreciarse, la diferencia más relevante es la supresión de las faltas menos graves, de manera que las cuantías equivalentes de la Ley estatal quedan englobadas, bien en las faltas leves, bien en las graves. Esta modulación del régimen establecido en la norma estatal no afecta por sí misma a las condiciones básicas de igualdad de los ciudadanos en el ejercicio de sus derechos y en el cumplimiento de sus deberes y, por ello, no introduce divergencias desproporcionadas respecto del régimen jurídico aplicable en otras partes del territorio. Máxime si se tiene en cuenta que, como ha quedado expuesto, a dichas sanciones no se han vinculado por parte del Estado determinadas conductas, sino que éstas deben ser determinadas por la propia Comunidad Autónoma, lo que a su vez está plenamente justificado puesto que la gravedad de las conductas dependerá en muchos casos de las condiciones concretas de cada uno de los espacios que se pretenden proteger.

Por ello, tampoco desde la perspectiva del artículo 149.1.1 puede concluirse la pretendida inconstitucionalidad de los artículos 27 y 28.1 de la Ley del Parlamento Vasco de Protección y Ordenación de la Biosfera de Urdaibai, y se debe descartar igualmente la del artículo 29.4 pues su impugnación estaba estrechamente relacionada con la de los mencionados preceptos» (f.j. 9).

Fallo: Desestimar el presente recurso de inconstitucionalidad. 
RESEÑA DE SENTENCIAS DEL TRIBUNAL CONSTITUCIONAL SOBRE LA ADMINISTRACIÓN LOCAL...

(Sentencia n. ${ }^{\circ}$ 156/1995, de 26 de octubre. Pleno. BOE 28-11-1995. J.D. González Campos).

3. Cuestión de inconstitucionalidad núm. 2.346/93, promovida por la Sección Primera de la Sala de lo Contencioso-Administrativo del Tribunal Superior de Justicia de Andalucía, en Granada, por supuesta inconstitucionalidad de los artículos. 5, 6 y 7, asi como de la disposición adicional primera de la Ley de la Comunidad Autónoma de Andalucía 2/1989, de 18 de julio, de espacios naturales protegidos, por poder vulnerar el artículo. 149.1.23.a C.E., en relación con lo dispuesto en los artículos 6 y 15 de la Ley 4/1989, de 27 de marzo, de conservación de los espacios naturales y de la flora y fauna silvestres. El TC desestima la cuestión.

«En el presente proceso, el órgano judicial cuestiona la constitucionalidad de los artículos 5, 6 y 7 y de la disposición adicional primera de la Ley de la Comunidad Autónoma de Andalucía 2/1989, de 18 de julio, de espacios naturales protegidos, por poder vulnerar el artículo 149.1.23.a C.E. en relación con lo establecido en los artículos 6 y 15 de la Ley 4/1989, de 27 de marzo, de conservación de los espacios naturales y de la flora y fauna silvestres; así como por ignorar el «derecho constitucional a la participación social", que sí habían respetado los aludidos preceptos de la Ley estatal. De acuerdo con lo dispuesto en dichos artículos de la Ley 4/1989 — cuyo carácter de normas básicas se declaró en su disposición adicional quinta-, la declaración de Parques y Reservas requerirá la previa elaboración y aprobacion del correspondiente Plan de Ordenación de los Recursos Naturales de la zona (artículo 15.1), si bien, excepcionalmente, podrá acordarse tal declaración sin la previa aprobación del Plan, "cuando existan razones que lo justifiquen y que se harán constar expresamente en la norma que los declare», en cuyo caso "deberá tramitarse en el plazo de un año, a partir de la declaración de Parque o Reserva el correspondiente Plan de Ordenación" (artículo 15.2). Por su parte, el art. 6 establece que "el procedimiento de elaboración de los Planes incluirá necesariamente trámites de audiencia a los interesados, información pública y consulta de los intereses sociales e institucionales afectados y de las asociaciones que persigan el logro de los principios» inspiradores de la Ley.

Frente a este régimen diseñado en tales normas básicas, la Ley autonómica procede a inventariar, sin la previa elaboración de Plan alguno, una larga serie de Reservas Naturales (artículo 5), Parajes Naturales (ar- 
tículo 6) y Parques Naturales (artículo 7), sin que se ofrezca otra justificación al respecto que la contenida en su disposicion adicional primera, esto es: «La declaración de los Parques y Reservas que se incluyen en esta Ley se considerará excepcional en cuanto a la elaboración y aprobación del correspondiente Plan de Ordenación de los Recursos Naturales que contempla la Ley $4 / 1989$, de conservación de los espacios naturales y de la flora y fauna silvestres, dada la urgencia de la adopción de medidas tendentes a la protección de los espacios naturales de Andalucía». Pues bien, a juicio del órgano judicial promotor de la cuestión de inconstitucionalidad que ahora ha de ocuparnos, en la medida en que la Ley impugnada ha declarado un elevado número de espacios naturales sin proceder a la elaboración previa de los Planes, y sin haber hecho constar las razones justificativas de tal omisión, cabe estimar que se han ignorado las bases estatales, ocasionando con ello la vulneración del artículo 149.1.23.a C.E. y, al tiempo, la del "derecho constitucional a la participación social» que aquéllas sí garantizaban. En el mismo sentido se manifiesta el Fiscal General del Estado» (f.j. 1).

«Entrando ya en el control de los preceptos autonómicos conviene hacer todavía dos precisiones. En primer lugar, que la alegada inconstitucionalidad del artículo 7 de la Ley autonómica es estrictamente por consecuencia, por lo que no será preciso argumentar nada específicamente respecto de dicho precepto. En efecto la eventual nulidad de la declaración de una serie de Parques Naturales en la que se agota el contenido del artículo 7 no será sino pura consecuencia respecto de lo que se resuelva en relación con la disposición adicional primera de la misma ley (...). También en este punto puede, pues, afirmarse que la eventual vulneración de lo previsto en el artículo 6 de la Ley estatal por parte de la Ley autonómica vendrá determinado por lo que se resuelva respecto de la disposición adicional primera. Podemos, así concluir que el problema a abordar en la presente cuestión se reduce al contraste de la disposición adicional primera de la Ley andaluza con lo dispuesto en el artículo 15.2 de la Ley 4/1989» (vid. f.j. 5).

«El artículo 15 de la Ley 4/1989 dispone lo siguiente:

«1. La declaración de los Parques y Reservas exigirá la previa elaboración y aprobación del correspondiente Plan de Ordenación de los Recursos Naturales de la Zona.

2. Excepcionalmente, podrán declararse Parques y Reservas sin la previa aprobación del Plan de ordenación de los Recursos Naturales, cuando existan razones que lo justifiquen y que se harán constar expre- 
RESEÑA DE SENTENCLAS DEL TRIBUNAL CONSTITUCIONAL SOBRE LA ADMINISTRACIÓN LOCAL...

samente en la norma que los declare. En este caso deberá tramitarse en el plazo de un año, a partir de la declaración de Parque o Reserva el correspondiente Plan de Ordenación".

Conviene ante todo recordar como, frente a la alegación de inconstitucionalidad precisamente de la Comunidad Autónoma de Andalucía, este Tribunal ha afirmado recientemente el carácter básico de lo dispuesto en el artículo 15 de la Ley 4/1989 en sus dos apartados (...)

El artículo 15 de la Ley 4/1989 contiene, ante todo, un mandato de inseparabilidad, por así decir, entre la calificación de un espacio natural y la elaboración del correspondiente Plan de ordenación de los Recursos Naturales de la zona, tal como se prevé esta figura en el artículo 4 de la Ley, como instrumento fundamental de integración de los principios inspiradores de la Ley recogidos en su artículo 2 y, señaladamente, la conciliación de la conservación del espacio con un ordenado aprovechamiento del mismo. La aprobación del Plan debe preceder, como regla, a la declaración del espacio. si bien puede también sucederle bajo determinadas condiciones, pero siempre en el plazo de un año. Sin Plan de ordenación, la declaración del espacio natural es en buena medida inoperante, siendo esto lo que el artículo 15 trata fundamentalmente de evitar y como, por lo demás, resulta también del artículo 13.1 de la Ley andaluza. Pero el Plan cumple además otra finalidad, cual es la prevista en el artículo 6, permitir la audiencia de los interesados, la información pública y la consulta de los intereses sociales afectados trámites que deben formar parte del procedimiento de elaboración del Plan.

El problema suscitado por la Ley autonómica no tiene que ver con la exclusión del Plan de ordenación, ni, consiguientemente, de ninguna de sus finalidades, sino, exclusivamente, con las dos posibilidades contempladas, respectivamente, en los dos apartados del citado artículo 15 la elaboración previa o la elaboración consiguiente, pero en el plazo de un año, a la declaración del espacio natural. En este sentido, el artículo 15 se encuentra diseñado en forma de una regla y de una excepción. La regla es la aprobación previa. La posibilidad alternativa, calificada como excepcional, y bajo ciertas condiciones, es la aprobación sucesiva, en el plazo de un año. La Ley de Andalucía de Espacios Naturales Protegidos, por medio de su disposición adicional primera se sitúa en esta segunda posibilidad, en la excepcional, cuyas condiciones la Sala cuestionante no considera cumplidas: "La declaración de los Parques y Reservas que se incluyen en esta Ley se considerará excepcional en cuanto a la elaboración y aprobación del correspondiente Plan de ordenación de los Recursos Naturales que contempla la Ley 4/1389 de con- 
servación de los espacios naturales y de la Flora y Fauna Silvestres, dada la urgencia de la adopción de medidas tendentes a la protección de los espacios naturales de Andalucía».

Del propio tenor literal de la norma básica se desprende que son dos las condiciones de cuyo cumplimiento depende que pueda legítimamente procederse a la declaración de Parques y Reservas naturales sin la previa aprobación del Plan, a saber: que existan razones que así lo justifiquen y que dichas razones se hagan constar expresamente en la norma que los declare. En lo que concierne al primero de los requisitos citados, es evidente que razón justificadora de la excepción, ciertamente, existe, toda vez que el legislador autonómico fundamenta su actuación en "la urgencia en la adopción de medidas tendentes a la protección de los espacios naturales de Andalucía». Debe, por lo demás, repararse en que las partes que apoyan la inconstitucionalidad de la Ley autonómica en ningún caso han mantenido que tal urgencia no pueda considerarse, en abstracto una válida razón objetiva justificadora de la excepción, o que, atendiendo a las circunstancias fácticas concurrentes, no cabía realmente, en el momento de aprobarse la Ley, constatarse la situación de urgencia pretendidamente legitimadora de la declaración de los Parques y Reservas Naturales sin la previa elaboración de los Planes. Y por lo que atañe a la condición según la cual han de mencionarse explícitamente en la norma las razones que justifican la excepción, hay pocas dudas que albergar acerca de que ha resultado igualmente satisfecha, habida cuenta de que la incorporación de la impugnada disposición adicional primera a la Ley autonómica tenía, precisamente, por solo y único objetivo el de hacer constar expresamente en la misma cuál era el excepcional motivo que permitía proceder a la inmediata declaración de los Parques y Reservas, obviando la previa elaboración de los Planes pertinentes.

Por tanto, si este requisito de la explicitación se ha cumplido y no se ha cuestionado que la urgencia pueda servir como válida razón objetiva justificadora de la excepción, la denunciada contradicción entre la norma estatal y la autonómica sólo podría fundamentarse en una determinada interpretación de la norma básica de la que pudiera inferirse algo más de lo que cabe deducir de sus propios términos. Así lo pondría de manifiesto la Fiscalía General del Estado, en cuya opinión el artículo 15 de la Ley estatal debe ser objeto de una interpretación rigurosa, y ello tanto por la utilización del término "excepcionalmente» con que comienza su párrafo segundo como por el hecho de que la excepción entrañe la exclusión de los trámites de audiencia a los interesados y de la información pública previos, de tal modo que, para entender respetado 
RESEÑA DE SENTENCLAS DEL TRIBUNAL CONSTITUCIONAL SOBRE LA ADMINISTRACIÓN LOCAL...

tal precepto, no puede considerarse suficiente que la norma autonómica se limite a remitirse al estado del medio ambiente en su ámbito territorial, sin contener Ia más mínima explicación de las razones de la urgencia en la adopción de las medidas protectoras que dicho estado reclama. Dicho más brevemente, la norma autonómica habría vulnerado las bases estatales, e incurrido, por ende, en inconstitucionalidad, por no haber alcanzado el grado suficiente o adecuado de explicación que, en virtud de tal interpretación, ha de entenderse exigido por la norma básica.

Esta argumentación no puede ser acogida. Ni el carácter excepcional de la medida ni la postergación de los trámites de audiencia e información pública a un momento posterior a la declaración de los Parques y Reservas - aspectos ambos que el legislador estatal ya tuvo presente, como es obvio, al aprobar el precepto- autorizan a añadir nuevos condicionantes -en este caso, un determinado nivel de suficiencia o adecuacion en la explicación de las razones justificadoras de la excepcióna aquéllos que puedan desprenderse lógicamente de la norma interpretada en sus propios términos. Por lo demás, ni siquiera puede aceptarse que la Ley cuestionada carezca de toda explicitación acerca de la aludida urgencia (...)

Ciertamente, la explicación de la urgencia, proclamada sin más en la Ley andaluza, pudo haber quedado en mayor medida individualizada, pero no podemos olvidar tampoco que no estamos, en este caso concreto, ante un supuesto de relación entre ley y reglamento, en el que éste deriva de aquélla toda su razón de ser, sino ante la que se da entre una ley estatal y una ley autonómica respecto del cumplimiento de un precepto básico contenido en aquélla. En este sentido, el precepto legal prevé la posibilidad de que, por excepción y con explicitación de las razones, la declaración del espacio natural no vaya precedida de la elaboración del Plan de ordenación de los recursos naturales. En resumen, el legislador andaluz ha considerado que la Ley 2/1989, de Espacios Naturales Protegidos, asume una posición excepcional en cuanto, como se declara en su artículo 1, su objeto no es otro que el de efectuar el «inventario de Espacios Naturales» de Andalucía, espacios que, como se proclama en la Exposición de Motivos de la Ley, ha venido degradándose paulatinamente. Esta decisión del legislador autonómico, contrastada con el correspondiente precepto básico, debe entenderse constitucionalmente legítima. Por todas estas razones, y como conclusión no cabe estimar que en este caso haya quedado vulnerada la norma básica contenida en el artículo 15 de la Ley 4/1989» (vid. f.j. 6). 
Fallo: Desestimar la presente cuestión de inconstitucionalidad.

(Sentencia n. ${ }^{\circ}$ 163/1995, de 8 de noviembre. Sala Segunda. BOE $14-$ 12-1995. P. Cruz Villalón. Votos particulares formulados por V. Gimeno Sendra y J. Gabaldón López). 